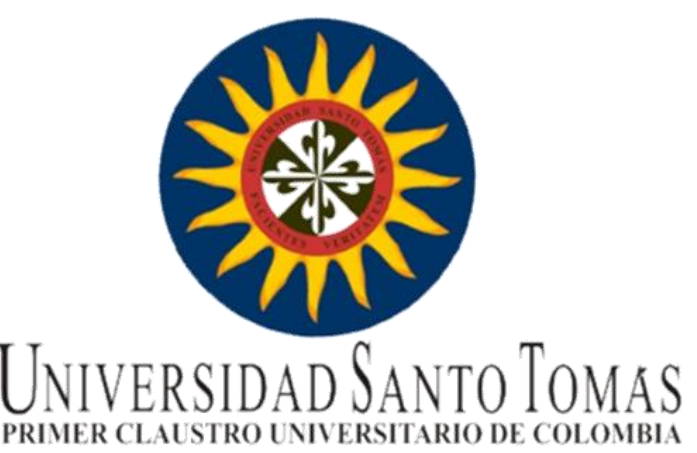

\title{
ANALISIS DEL SISTEMA PENSIONAL EN COLOMBIA DESDE LA METODOLOGIA DE RANGO REESCALADO (R/S) Y LA LEY 1328 DE 2009'
}

\section{Héctor David Nieto Martínez ${ }^{2}$}

\author{
Universidad Santo Tomás \\ Facultad de Economía \\ Maestría en Ciencias Económicas \\ Bogotá, Colombia \\ 2017
}

\footnotetext{
${ }^{1}$ Proyecto para optar el título de Magister en Ciencias Económicas - Universidad Santo Tomas de Aquino. ${ }^{2}$ Administrador de Empresas - Universidad El Bosque, Docente de la Universidad El Bosque, Financial Planner - Old Mutual Colombia.
} 


\section{ANALISIS DEL SISTEMA PENSIONAL EN COLOMBIA DESDE LA METODOLOGIA DE RANGO REESCALADO (R/S) Y LA LEY 1328 DE 2009}

\section{Héctor David Nieto Martínez}

Tesis presentada como requisito parcial para optar al título de:

Magister en Ciencias Económicas

Director:

Doctor Gustavo Junca

Línea de Investigación:

Economía Financiera

\section{Universidad Santo Tomás}

Facultad de Economía

Maestría en Ciencias Económicas

Bogotá, Colombia 2017 


\section{CONTENIDO}

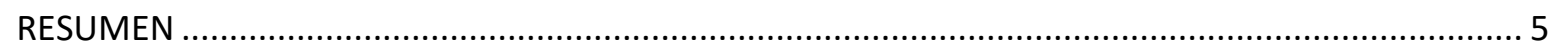

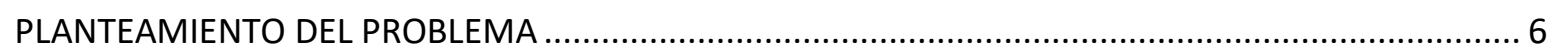

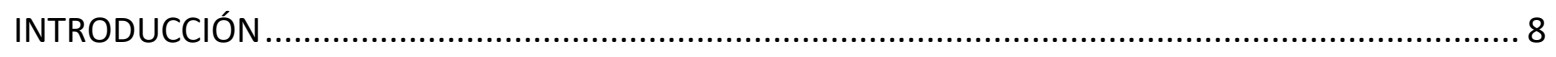

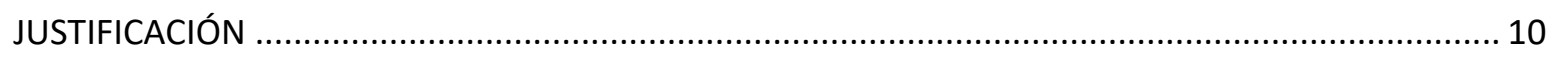

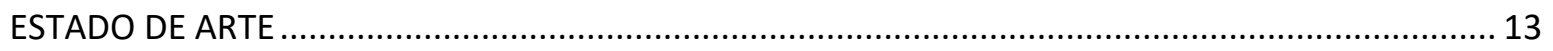

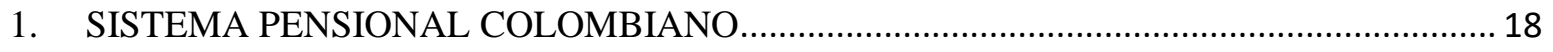

1.1. ANTECEDENTES REFORMA PENSIONAL EN COLOMBIA ................................... 18

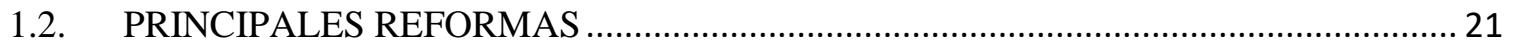

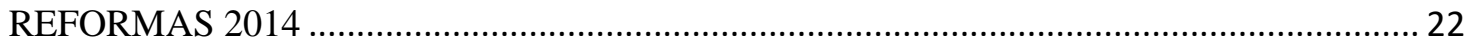

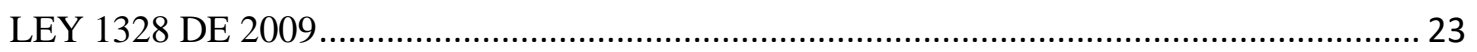

1.3. REGIMENES DE PENSIONES Y SU CARACTERIZACION ACTUAL EN

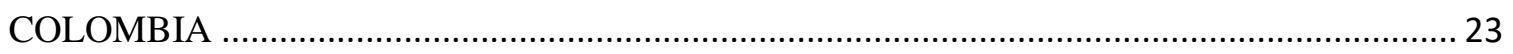

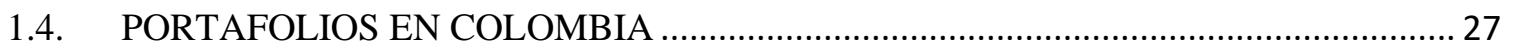

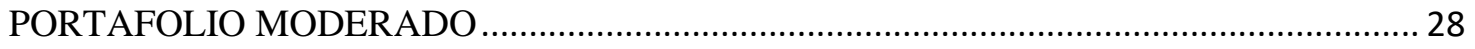

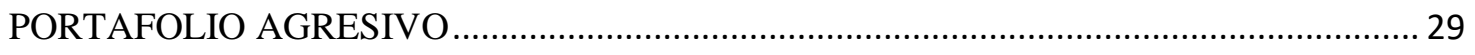

2. PERSISTENCIA Y COMPORTAMIENTOS IRREGULARES EN LOS MERCADOS ........ 30

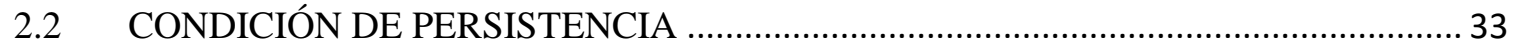

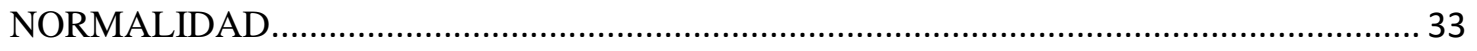

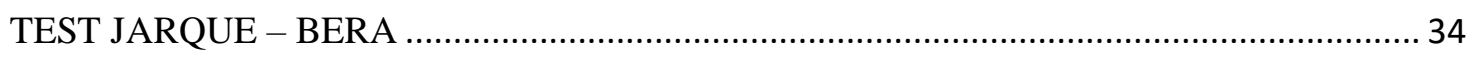

TEST DE SHAPIRO - WILK ..................................................................................... 34

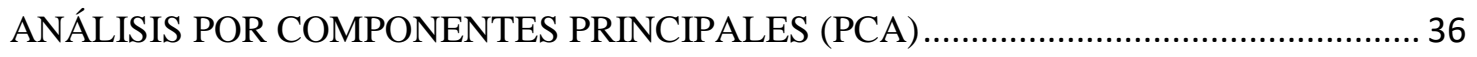

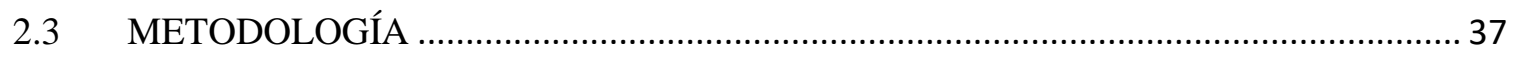

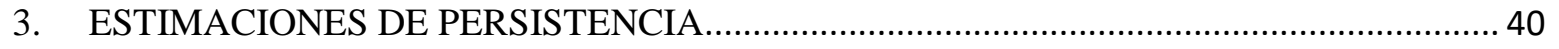

3.1 APLICACIÓN DEL MODELO DE RANGO REESCALADO (R/S) ............................ 40

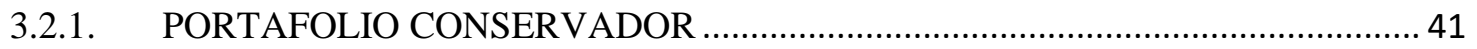

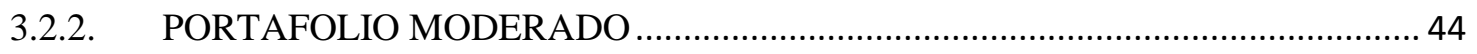

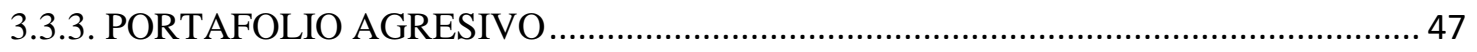

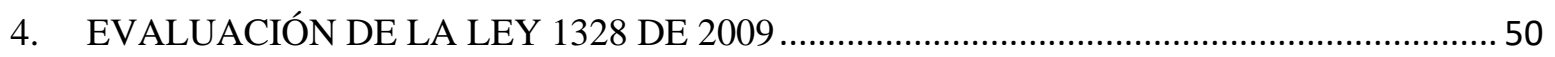

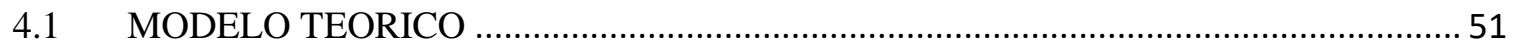

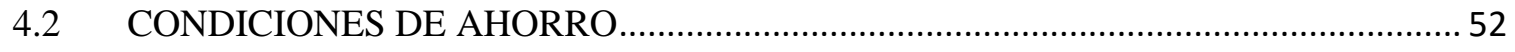

BARRERAS PARA EL AHORRO DE LARGO PLAZO..................................................... 52 


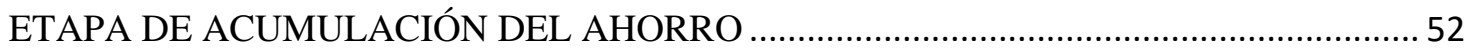

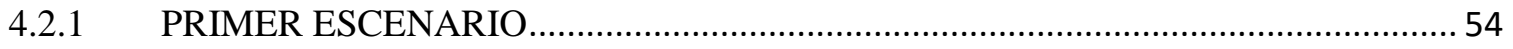

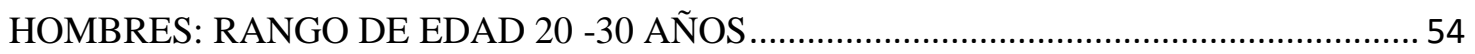

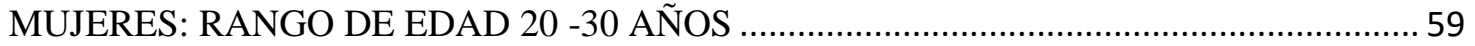

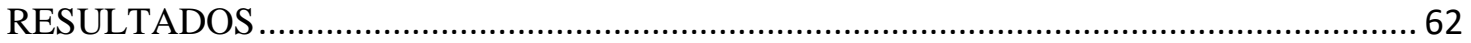

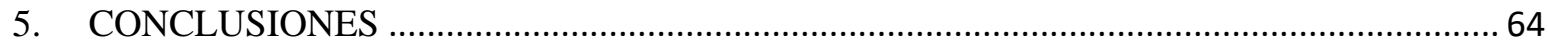

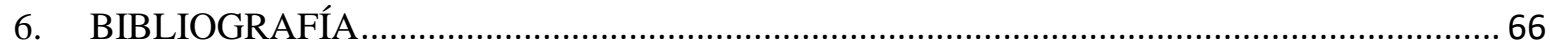

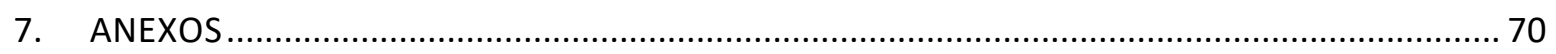




\section{RESUMEN}

En los últimos años, el sector financiero y pensional a nivel nacional han posicionado su relevancia, en términos de las decisiones de inversión, ahorro y consumo tanto de las empresas como de las familias; esto, fundamentado en diversos estudios que intentan explicar factores de comportamientos de estos mercados, permitiendo así observar la capacidad que tienen diferentes modelos y aproximaciones a la reducción de sesgos de información que muestra el mercado.

Por ello, se hace necesario que se realice una revisión, acerca de las diferentes aplicaciones que han presentado los mercados financieros, para poder determinar si existe la probabilidad de que puedan ser aplicados a un análisis del comportamiento pensional en Colombia, con el objetivo principal de aumentar la confiabilidad y certeza de los usuarios para tomar las mejores decisiones. A partir de esta información, el estudio se enmarca en analizar los valores de unidad de los fondos de pensiones en Colombia, a partir del análisis de Rango Reescalado y la Ley 1328 de 2009.

Como primera medida, se analizará el comportamiento de los valores de unidad (Precios), de los portafolios que actualmente existen en Colombia (Conservador, Moderado y Agresivo), a partir de la metodología de Rango Reescalado (R/S), basado en las teorías elaboradas por autores como Hurst (1950), Mandelbrot (1951), Lorenz (1960), entre otros. Definiendo, que se puede analizar el comportamiento de dichos activos de forma diferente a los supuestos de la teoría de portafolios eficientes y complementando el análisis a partir de la ley 1328 de 2009, permitiendo entender el funcionamiento de este tipo de mercados, en el ámbito financiero y pensional. 


\section{PLANTEAMIENTO DEL PROBLEMA}

La generación de información en diversas áreas a nivel mundial se ha convertido en uno de los aspectos más relevantes a la hora de hablar del crecimiento económico para los países. Dado que el Mercado de información y económico, es un medio para canalizar recursos de agentes superavitarios hacia otros cuya posición es deficitaria, para que éstos últimos, realicen algún tipo de proyecto y/o semejante que finalmente incremente la producción total. Esto, es una suerte de ahorro que funge como fuente de financiamiento para la inversión, convirtiéndose en un factor determinante de crecimiento económico (Brianto, 2010).

Dada a la importancia que tiene la situación pensional sobre el comportamiento de los mercados de valores, sobre las economías y las decisiones de los agentes, es importante resaltar cómo funciona el sistema de pensiones en Colombia a través del mercado de capitales, encontrando, que existen ciertas inconformidades, del comportamiento del sistema pensional, por lo cual hoy se ve afectado el modelo pensional en el país, y las afirmaciones que han realizado entidades como (Botero, 2017) quien advierte que "Una gran proporción de ancianos tendrán una vejez pobre, la vejez es la principal causa de pobreza en Colombia y es un problema que está creciendo”, los datos anunciados por (Oliveira, 2017), quien manifiesta que "existen 21 millones de trabajadores, solo 7 millones cotizan y solo dos millones logran pensionarse”, encontrando que existe un problema latente que tarde o temprano afectara y desencadenará un gran impacto económico y social en el país.

De tal forma, se evidencia la importancia de analizar el comportamiento de estos activos (Portafolios de pensiones), respondiendo a la pregunta si existe una forma diferente 
de analizar el comportamiento de este tipo de mercados, así como también, si se puede lograr encontrar soluciones, que permitan una mejor toma de decisiones por parte de los colombianos, teniendo como base el conocimiento y entendimiento de la información y permitiendo ayudar a una mejor administración y sostenibilidad del sistema pensional a largo plazo para las personas y la nación.

Además, se puede generar para brindar respuesta a la pregunta de investigación, realizando una revisión a fondo de literatura de diferentes estudios que han evidenciado como la aplicación en los mercados de diferentes modelos, permiten aumentar la fiabilidad y el conocimiento del comportamiento de los mismos. Por ello se han desarrollado diferentes componentes metodológicos que permitirán analizar el mercado pensional, dado a la falta de estudios que existen en este sector; como lo son modelos aplicados de no normalidad en el sector financiero y la evaluación del Ley 1389 de 2009, para determinar el funcionamiento del sistema.

Por tanto, se hará la evaluación de los diferentes estudios y aplicaciones de los modelos de persistencia y portafolios eficientes para el mercado colombiano, que permita observar la presencia o existencia de condiciones irregulares dentro de los mercados de capitales, a causa de diferentes choques económicos y financieros, descartando las condiciones iniciales de normalidad en el comportamiento de la serie de tiempo, de los rendimientos de los portafolios de los fondos de pensiones que actualmente existen en Colombia (Conservador, Moderado y Agresivo). Manifestándose así, la gran importancia que representaría para las personas que invierten dinero, logrando poder predecir las tendencias del mercado y más interesante aún, conocer con antelación el precio de cotización de las FPOB (Rufino \& Jovanovich, 2014) 


\section{INTRODUCCIÓN}

El presente documento tiene como eje central el análisis de asimetrías de información, acerca del funciona del sistema pensional colombiano, donde se aborda la temática desde la importancia que tiene el conocimiento y funcionamiento, por parte de las entidades privadas y de aquellas personas que actualmente cotizan dentro del sistema de Régimen de Ahorro Individual de Pensiones (RAIS).

Este análisis se logra enmarcar, teniendo como base los periodos comprendido entre los años 2010 al 2016, los cuales han sido gran evidencia histórica del comportamiento de los portafolios en los fondos de pensiones, logrando poner en manifiesto los cambios en cuanto a los términos de los portafolios en los fondos de pensiones en Colombia.

Teniendo en cuenta lo anterior, es importante destacar la necesidad de abordar esta temática desde la concepción histórica del sistema pensional colombiano, cuáles han sido las reformas significativas que se han implementado después de la entrada en vigor de la ley 100 de 1993 y que portafolios existen actualmente, luego de analizar la ley 1328 de 2009, la cual trajo consigo la concepción del esquema multiportafolios, todo ello ligado, a las brechas de información, que presentan las bases históricas del país, que se presentan como incompletas o confidenciales en diversos temas y ocasiones.

Con esta base de información, se abordarán y aplicaran importantes estudios que se han realizado acerca de la metodología de Rango Reescalado, permitiendo dar una visión abierta de la aplicación de este tipo de metodologías en los diversos mercados, ampliando la información, acerca de si se han evidenciado este tipo de análisis en los mercados pensionales. 
Todo ello con el fin, de establecer si se puede analizar el sistema pensional a partir de la aplicación de modelos de persistencia y análisis de los resultados de mesadas pensionales, tomando como punto de partida el comportamiento de los portafolios de inversiones que actualmente existen en los fondos de pensiones de ahorro individual en Colombia.

Concluyendo se podría evidenciar, nuevas propuestas de administración, a partir de los modelos de gestión y valoración del riesgo, así como nuevas propuestas de políticas de ahorro que permitan aumentar la calidad de vida de las personas, vía las mesadas pensionales obtenidos en el sistema pensional colombiano. 


\section{JUSTIFICACIÓN}

Afirmaciones que han realizad como Botero (2017) quien advierte que "Una gran proporción de ancianos tendrán una vejez pobre, la vejez es la principal causa de pobreza en Colombia y es un problema que está creciendo”, los datos anunciados por Oliveira (2017) quien manifiesta que "existen 21 millones de trabajadores, solo 7 millones cotizan y solo dos millones logran pensionarse”, y estudios que afirman que solo el $23 \%$ de las personas adultas cuentan con una pensión, igualmente Oliveira (2017) define que "Es necesario que se realice una reforma pensional, teniendo en cuenta la cobertura en pensiones y la sostenibilidad financiera”, permiten la realización de debates acerca de cómo empezar a incentivar el ahorro en cada uno de los colombianos, lo cual abre el espacio para generar este tipo de investigaciones que permitan fundamentar, como se pueden mejorar estas clases de problemáticas a nivel de dos agentes como lo son: la administradora y sus afiliados, desde un análisis financiero y matemático.

Por ello, es de vital importancia identificar que muchos de los problemas que poseen los mercados, se debe a la falta de información por parte de los agentes, acerca del funcionamiento de este tipo de estructuras, además de la existencia de alternativas adicionales que mejoren la administración y la toma de decisiones de los involucrados, buscando obtener el mayor beneficio posible, acorde a sus condiciones sociales y económicas.

Por ende, la limitación por parte de la administradora que basa sus estudios y/o estimaciones en el comportamiento del mercado financiero, cada vez resulta más importante para entender como la dinámica de los índices y el rendimiento de los activos dentro del mercado, fluctúan y se comportan a través del tiempo. Muchas de las investigaciones 
realizadas, se basan en que el mercado sigue un patrón de movimiento browniano, basado en la teoría de mercados eficientes expuesta por Fama (1969).

Por consiguiente, es fundamental analizar cada uno de los estudios que han permitido ampliar la información, a partir de modelos adicionales que busquen mejorar el análisis de las estructuras financieras. A pesar de la escasez de documentación para realizar una investigación, se logra identificar si en los valores de unidad de los portafolios de los fondos de pensiones, se evidencian características de persistencia o evaluación del comportamiento de estos fondos a partir de la ley 1389 de 2009, logrando cambiar la forma de analizar el mercado. En los últimos años se han realizado investigaciones basadas en una propuesta alternativa de análisis desarrollado por Peters (1994), denominada como análisis de mercados fractales, la cual, se encuentra basada en el análisis de geometría fractal expuesto por Mandelbrot (1966) y la teoría de caos; teniendo como objetivo el poder analizar estructuras complejas a través de metodologías simples, que permiten relacionar un modelo con las variables expuestas en su totalidad en el mercado.

Diversos estudios realizados para Latinoamérica, arrojan resultados de la existencia de estructuras irregulares dentro de los sistemas financieros, así mismo se evidencia existencia de persistencia y memoria a largo plazo, en tasas de interés, tasas de cambio y diversos índices bursátiles de los principales mercados de capitales que según (Bartoli, 2005) y (Nawrocki, 1995) manifiestan este tipo de irregularidades.

Como se ha mencionado, este tipo de estudios presenta una gran escasez de trabajos en el área que apliquen metodologías como Rango Reescalado (R/S) en el sector pensional, generado así, que en la actualidad no se posea información acerca de las condiciones futuras de vida de una persona (mesada pensional, bajo supuestos), por ello, el ampliar el campo de 
estudios de este tipo de trabajos, permite complementar resultados encontrados en la aplicación y estimación de otro tipo de modelos y las necesidades de expandir los estudios de forma más rigurosa no solo en los sistemas del sistema financiero, sino en comportamientos que pueden evidenciar cambios estructurales dentro de las reformas y continuidad de los fondos de pensiones. 


\section{ESTADO DE ARTE}

Existen múltiples estudios aplicados que han encontrado evidencia de estructuras nolineales o en sistemas dinámicos, aplicados a diversas áreas de estudio que se presentan a continuación:

Existen diversas herramientas y metodologías para medir persistencia a largo plazo, mencionadas por León \& Vivas (2010), como lo son la regresión por periodogramas, Wavelets entre otros, sin embargo, el uso del Rango Reescalado, ha sido utilizado por varios autores dada su robustez y su utilidad para detectar este tipo de fenómenos, adicionalmente por su facilidad en el cálculo permite aumentar el uso dentro de los análisis del mercado de capitales.

Los estudios sobre precontingencia ambiental realizados por (Vucovich, Audelo, Estela, \& Carlos, 2015), determinaron que a partir del exponente de Hurst, diagramas de fases y el exponente de Lyapunov, existen estructuras caóticas para determinar y predecir situaciones de precontigencia en periodos futuros.

Muchos de los problemas analizados en el comportamiento humano y en los comportamientos sociales, encuentran evidencia de fenómenos irregulares que dan respuesta a la premisa de la existencia de estructuras caóticas dentro de los sistemas, no solo económicos sino sociales y culturales, encontrando una alta aplicación y alcance del estudio a realizar.

El Rango reescalado desarrollado por Edwin Hurst, permite la medición de las desviaciones (riesgo) de una serie con respecto a su promedio (rentabilidad), teniendo en 
cuenta diferentes ventanas de tiempo. Como finalidad última, se basa en el cálculo del rango de una serie a través del tiempo, teniendo como variable exógena el efecto de tendencia (Rodriguez, 2011).

Las condiciones que satisfacen el modelo expuesto inicialmente por Hurst (1951), es complementado por Mandelbrot (1966), dado que encontró que los niveles de persistencia dentro de un sistema financiero se determinaban a partir de un exponente que estuviera entre $0,5<\mathrm{H}<1$, lo cual indica que sucesos o eventos positivos dentro de un sistema en un periodo anterior, será replicado con una alta probabilidad de repetirse. Si las condiciones son $0,<\mathrm{H}<0$, los eventos sucederán de forma inversa al periodo inmediatamente anterior y si $\mathrm{H}=0,5$, el proceso mantiene un movimiento browniano y aleatoriedad, donde no existirá información completa entre los agentes que se encuentran interactuando en el mercado, haciendo este de modelo perfecto, donde no se podrán predecir los resultados e impactos futuros de los retornos.

A través del tiempo, se han realizado estudios que han demostrado que el comportamiento de activos dentro del sistema financiero, presentan inconsistencias frente a las teorías desarrolladas por Eugene Fama. Por ellos, muchas investigaciones se han centrado en analizar estos fenómenos que permitan identificar y entender de una forma más completa este tipo de comportamientos en el mercado.

En los estudios realizados por Bachelier (1900), se logra analizar por primera vez el comportamiento de los activos financieros, en busca de caminatas aleatorias en los cambios de precios. Caso particular fue el estudiado por Sadique \& Silvapulle (2001), quienes realizaron estudios de persistencia en las variaciones de precios de diferentes países. 
Así mismo, algunos estudios realizados a través de modelos lineales autorregresivos y con modelo ARIMA, fueron desarrollados por Box \& Jenkins (1986) y Engle (1982), quienes identificaron modelos que permitían encontrar problemas de heterocedasticidad.

Para América Latina muchos de los estudios se han basado en la metodología de R/S, lo cual, se ha vuelto una de las metodologías que brinda ayuda para la identificación de fenómenos irregulares dentro de los sistemas financieros. En estudios realizados por Espinosa (2007), se pudo confirmar que en índices de países latinoamericanos existe persistencia de largo plazo; además, se hallaron resultados similares en los análisis del índice de Down Jones realizados por Greene y fielitz (1977), quienes determinaron que existe memoria a largo plazo en dicho índice.

Por otro lado, Peters (1994), logro encontrar e identificar, que a través de la metodología R/S, existe persistencia en el índice de S\&P 500. Por su parte, estudios realizados de memoria a en el mercado de monedas que fueron realizados por Kyaw, Los y Zong (2004), se logró encontrar dependencia de largo plazo, el cual, fue calculado a través del exponente de Hurst, en todos los índices bursátiles excepto el tipo de cambio de México y el mercado colombiano.

Espinosa (2007) obtuvo resultados similares a las investigaciones realizadas por Los \& Yu (2005), quienes usaron como medida inicial los precios de cierre del mercado chino, encontrando, fenómenos de persistencia a largo plazo. Caso contrario, a los resultados obtenidos en Europa, los cuales no logran ser consistentes para determinar dependencia en las series. (Espinosa, 2007). 
Al tomar como ejemplo a Lipka y Los (2003), que, al realizar su estudio, toman como referencia los índices que corresponden al país europeo, incluyendo en su estudio al IBEX 35 y el FTSE 100. Aplicando diferentes metodologías para el cálculo del exponente H se encontró que el exponente varía entre 0.22 y 0.56 (Espinosa, 2007).

Para el mercado colombiano estudios como Duarte, Sierra \& Peréz (2014), evidencian que el mercado colombiano presenta series irregulares en sus comportamientos de tiempos prolongados, calculadas por medio de modelos de Exponente de Hurst y modelos lineales.

\section{ARIMA - GARCH.}

Los fenómenos de persistencia se presentan dentro de los activos financieros, es así, que se deduce que los resultados de los rendimientos de los activos pasados pueden presentar una incidencia en los resultados futuros, teniendo en cuenta que se puede presentar a largo y corto plazo. Dichos fenómenos, pueden resultar de vital importancia para el inversionista quien determina su horizonte con respecto a las condiciones de su comportamiento frente al riesgo.

Teniendo en cuenta lo anterior, se puede determinar que los procesos aleatorios resultan sumamente importantes en un alto porcentaje en los análisis de fenómenos naturales. En el año 1828, el botánico Robert Brown, puso en manifiesto en un documento, un estudio realizado acerca del movimiento generado por las partículas del polen, donde se observaba por medio de un microscopio, que dicho movimiento parecía moverse de manera errática y 
continua, haciendo que su movimiento pasado, mostraba que no afectaría la dirección futura (Rodriguez, 2011).

Bajo los resultados obtenidos se puede definir, que existe un gran avance y soporte para pensar que los mercados financieros muestran cierta estabilidad a través del tiempo, convirtiéndose en una fuente de cálculo para el desarrollo de nuevas estrategias de inversión y análisis para las variables económicas y financieras. 


\section{SISTEMA PENSIONAL COLOMBIANO}

En el siguiente capítulo se abordará los antecedentes que se han presentado dentro del sistema pensional colombiano, importantes reformas, caracterización de los regímenes pensionales en Colombia y su estructura, con el fin de entender como ha sido el funcionamiento del sistema hasta el día de hoy. Así mismo se nombrarán las entidades que actualmente existen en Colombia para el recado y pago de pensiones. Las cuales de dividen en dos regímenes Régimen de Ahorro Individual (RAIS) (Old Mutual, Porvenir, Protección) y Régimen de Prima Media (RPM) y las principales estructuras de inversión.

\subsection{ANTECEDENTES REFORMA PENSIONAL EN COLOMBIA}

$\mathrm{Al}$ ahondar en el tema del sistema pensional colombiano, se debe iniciar con los tres antecedentes más importantes de este, que tuvieron lugar en el periodo de 1945 a 1947, iniciando con la creación del Sistema de Seguridad Social de Colombia, también, se dio origen al Instituto Colombiano de Seguros Sociales y a la caja nacional de previsión, mejor conocida como CAJANAL, esto dio lugar a la creación de cerca de 1040 pequeñas cajas, dirigidas a empleados del sector público; por otro lado, la Ley 6 de 1945 que institucionalizo los derechos que abarcaba salud, pensión y riesgos profesionales. Todo ello, dio como origen al primer régimen pensional de prima media o de reparto con beneficio definido, donde los contribuyentes aportaban a un fondo, de donde era pagado lo correspondiente a los pensionados. 
A raíz de los hechos anteriormente descritos, a través de los años, el sistema pensional empezó a emerger y evolucionar, es así, que en el año de 1946 gracias a la Ley 90, se logró instaurar el sistema de seguridad social, siendo este patrimonio autónomo que llego a reconocer los derechos de prestaciones de los trabajadores. 21 años después, en 1967 se reajustaron los reglamentos de pensiones de todos los empleados del sector privado de Colombia, tornándose un marco de obligatoriedad e implantando al Instituto Colombiano le los Seguros Sociales ICSS como administrador de los mismos, que después, en el año 77 se denominaría Instituto de Seguros Sociales ISS.

La creación e implementación del régimen de prima media, brindó beneficios a gran parte de los empleados que la conformaban y formó los cimientos del sistema de pensiones, pero poco a poco fue demostrando, un detrimento dado a que es considerada un fondo común, estas falencias se dieron por falta e inadecuado manejo en el área administrativa, al entregar grandes beneficios a todos aquellos que pertenecían al sistema, otorgándoles la pensión a una temprana edad.

Esto, genero, que los recursos empezaran a escasear, se manifestó inestabilidad en el área financiera, una gran inequidad, poca cobertura ya que solo abarcaba el $21 \%$ de los trabajadores. Todo ello, aconteció gracias a diversos factores, entre los cuales los más sobresalientes fueron la falta de crecimiento de la tasa de cotización, el incumplimiento por parte del Estado en cuanto a cotizaciones, los grandes beneficios a contribuyentes, la amplia oferta de cajas y regímenes, por último, las fluctuaciones demográficas que generaron mayor inestabilidad.

Es así, que cada una de estas señales y síntomas, daban paso a un sistema enfermo, que desangraba los recursos de los aportantes y decaía cada vez más, llevando a que fuera 
necesaria la implementación de una fuerte modificación en la normatividad legislativa, que regía al sistema pensional en la década de 1990.

Al introducirse una nueva constitución en 1991, se hizo más fácil y factible realizar los correctivos al sistema, los cuales fueron evidentes dos años después con la promulgación de la Ley 100 de 1993, en la cual, se sentó el precedente de un sistema de pensión y salud robusto que mejoraría notablemente las condiciones que el sistema brindaba a los aportantes.

Por ello, las modificaciones se centraron en lograr los objetivos propuestos, los cuales se encontraban destinados en beneficios para los colombianos, donde se buscó la ampliación de la cobertura y la equidad, la disminución del costo en el área de manejo administrativo del sistema, teniendo una visión a futuro de sostenibilidad corporativa, una estabilidad en el área fiscal, el cambio de edad en la cual se lograba obtener la pensión a una edad más avanzada, basándose en los datos demográficos y esperanza de vida de mujeres y hombres del país.

También, se logró hallar un equilibrio entre los contribuyentes y los beneficiarios, se creó un incentivo al ahorro y eficiencia en el manejo de recursos, pero, la mayor modificación se enfocó, en la institución de un sistema dual, al instaurar dos regímenes excluyentes entre sí, el primero de ellos siguió siendo el de prima media, donde concentraron las diferentes cajas, Cajanal y el Instituto de Seguridad Social, y por otro lado, un régimen de ahorro individual teniendo en cuenta la solidaridad, y siendo dirigido por AFP, Administradoras de fondos de pensiones, con carácter privado.

Dicha ley, logra un sistema integral, tanto de entidades privadas como públicas, elimina el poder del Estado al ser el único que posee el manejo de la seguridad social, y se 
implanta la privatización con el ahorro individual. Cabe recordar, que los empleados se les otorgo el libre albedrio de elección de régimen.

Pero, en medio de la reforma, se encontró que existían, algunas cajas que debían ser excluidas al tener un manejo de recursos de Estado que generaban desigualdad, en las cuales se concentraban funcionarios de regímenes especiales como lo son Las Fuerzas Armadas, Presidencia, Policía Nacional, Congresistas, Ecopetrol y el Magisterio.

En conclusión, a los 10 años de realizadas las modificaciones, fue necesario implementar una nueva Ley, la 797 de 2003, la cual apoyó a mejorar el manejo de recursos del Estado, optimizar beneficios para los pensionados, aumentar la tasa de cotización, incremento en edad para obtener la pensión, minimizar las comisiones de las asociaciones de fondo privado, cambios en tasas de liquidación de pensiones, reducción del periodo de transición, además la Ley 860 del mismo año, sano algunas inconstitucionalidades de la ley anterior, y adicionó los beneficios obtenidos al sufrir invalides ocasionado por accidentes o enfermedades.

\subsection{PRINCIPALES REFORMAS}

Como consecuencia a los diversos cambios que se presentaron en el país en el sector pensional, fue necesario implementar diferentes modificaciones al régimen pensional en Colombia, por ello se presenta la descripción de la cada una de ella buscando resaltar los cambios más importantes que se han dado en el país: 


\section{REFORMAS 2005}

Se realiza la eliminación según el acto legislativo 001 de 2005 de los regímenes especiales, basándose en la búsqueda de homogeneización de condiciones y requisitos, para proporcionar equidad a la sociedad e incrementar ahorro fiscal y mejorar el manejo de recursos. Solo queda vigente la Fuerza Pública y Presidencia. Otro de los cambios, se enfocó en dejar claro, la imposibilidad de cobrar impuestos por pensiones. La última modificación estableció que ninguna pensión puede ser menor a un salario mínimo, además, desde agosto del año 2010 no podrían pagarse pensiones mayores a 25 SMMLV.

\section{REFORMAS 2014}

Se llevó a cabo la modificación en cuanto a prolongación de semanas y edad para la obtención de pensión por vejez: 1300 semanas e implantación de 57 años para mujeres y 62 para hombres.

De esta manera, los regímenes pensionales y sus condiciones han ido evolucionando cada año, implementando cambios necesarios para mejorar y garantizar el sostenimiento del sistema tanto pensional como financiero, racionalizando los recursos y buscando equidad, homogenización de condiciones, siempre con el fin último de respetar los derechos humanos. A continuación, se presenta un cuadro comparativo con el estado actual, para el año 2016, de los regímenes vigentes para los colombianos: 


\section{LEY 1328 DE 2009}

El sector financiero, requiere de un conjunto de regulaciones que permitan, que cada una de las modificaciones y movimientos que se generen, no tengan perjuicios para ninguno de los actores que se encuentren vinculados, por ello se crea, un régimen de protección dirigido a los consumidores financieros con relación a las entidades de la superintendencia Financiera de Colombia, llamado la Ley 1328 de 2009.

Dicha ley, tiene como principal objetivo, establecer reglas y principios que protejan tanto consumidores, entidades, asegurador y mercado de valores, las cuales se basan en los principios de debida diligencia, libertad de elección, transparencia e información cierta, suficiente y oportuna, responsabilidad de las entidades vigiladas en el trámite de quejas, manejo adecuado de los conflictos de interés y la educación para el consumidor financiero.

Esta ley se enfoca en dar forma a la caracterización del esquema de multifondos, los cuales serán administrados por los fondos del Régimen de Ahorro Individual con Solidaridad. Adicionalmente, cómo el gobierno controlará e interpondrá la rentabilidad mínima garantizada para cada uno de los afiliados.

\subsection{REGIMENES DE PENSIONES Y SU CARACTERIZACION ACTUAL EN COLOMBIA}

En la actualidad, Colombia posee dos regímenes principales para la recaudación de pensiones, en primer lugar, se encuentra el régimen solidario de prima media, en el cual, se evidencia un sistema donde los beneficiarios logran su pensión de invalidez, sobrevivientes 
o de vejez una clase de sistema de pensión mediante la cual los afiliados o sus beneficiarios obtienen una pensión ante eventualidades como indemnización, vejez, invalidez o de sobrevivientes. Este régimen, se encuentra una administradora única y exclusivamente por la entidad denominada Colpensiones.

Este régimen, posee características fundamentales tales como que es un fondo común en pro de beneficios para la población en general, es por ello, que es financiado por transferencias del Gobierno Nacional y recursos de un fondo común, que soportan el pago oportuno. Por otro lado, el valor de la pensión será proporcional al número de semanas cotizadas, edad y al salario promedio que se haya tenido durante los últimos 10 año, siendo una pensión para toda la vida, si y solo si, se cumplen con todos los requisitos requeridos, mencionados anteriormente.

El segundo régimen, esta denominado como de ahorro individual, el cual es administrado por sociedades administradoras de fondos de pensiones llamadas AFP.

Al igual que la prima media, el ahorro individual, posee características haciéndolo un régimen único, al poseer un valor de pensión que depende directamente del capital que se logre ahorrar durante un tiempo determinado, los requisitos para lograr la pensión se basan en un retiro programado, una renta vitalicia o la unión de los dos anteriores: retiro programado con renta vitalicia.

También, este régimen tiene como característica, que estas pensiones son pagas con cada uno de los ahorros que realicen los afiliados y estas, pueden acumularse y puede ser heredara. Cabe recordar, que en la actualidad existen cinco fondos de pensiones en Colombia, distribuidos en cuatro fondos privados y uno solo como fondo público, los cuales se 
caracterizan por los tipos de prestaciones y la administración de los capitales de las pensiones de los colombianos.

Por ello, los fondos privados son capitales autónomos de las personas, es decir, los recursos son propiamente de las personas, mientras que en el público se manejan los recursos como fondo común. Estos cuatro fondos de pensiones de inversión privada son Porvenir, Protección, Colfondos y Old Mutual, los cuales manejan los recursos de los colombianos que no se encuentran afiliados al régimen público, en la siguiente tabla se muestra la cantidad de afiliados que se encuentran actualmente en estos fondos.

A continuación, se presentan las diferencias y características de los dos regímenes establecidos por ley:

Tabla 1. Características regímenes pensionales actuales en Colombia

\begin{tabular}{|l|c|}
\hline \multicolumn{2}{|c|}{ REGIMENES PENSIONALES EN COLOMBIA } \\
\hline REGIMEN PRIMA MEDIA & REGIMEN AHORRO INDIVIDUAL \\
\hline a. Los recursos son manejados como & a. Los recursos son propios de cada \\
un fondo común. Es decir & afiliado. \\
\hline b. No se pueden hacer aportes & c. $\quad$ El afiliado se puede pensionar antes \\
adicionales, para aumentar mesada & de tiempo, dependiendo de s capital \\
pensional. & acumulado. \\
\hline d. La mesada pensional se liquida con & e. Puede realizar aportes adicionales \\
base a los salarios cotizados en los & para aumentar la mesada pensional. \\
últimos 10 años. &
\end{tabular}




\begin{tabular}{|c|c|}
\hline & $\begin{array}{l}\text { Si el afiliado fallece el capital } \\
\text { ahorrado puede ser heredado. }\end{array}$ \\
\hline $\begin{array}{l}\text { f. Solo puede obtener su pensión, } \\
\text { cuando se cumpla la edad y semanas } \\
\text { establecidas por la ley (Mujer } 57 \\
\text { años y hombre 62). }\end{array}$ & $\begin{array}{l}\text { g. Si cuenta con capital suficiente y } \\
\text { superior a los establecido por laye, le } \\
\text { devolverán el capital que sobre. }\end{array}$ \\
\hline $\begin{array}{l}\text { h. Si el afiliado no reúne las } \\
\text { condiciones para una pensión, e o } \\
\text { sus beneficiarios tendrán derecho a } \\
\text { indemnización sustitutiva. }\end{array}$ & $\begin{array}{l}\text { i. Si no se cumple las condiciones para } \\
\text { pensión, la AFP le devolverá sus } \\
\text { aportes, junto al valor del bono, en } \\
\text { caso de que sea el caso. }\end{array}$ \\
\hline
\end{tabular}

Fuente: Autor con base a datos de Colfondos (2017)

Al ser el régimen de ahorro individual el de más acogida entre los colombianos, es importante especificar, como se encuentra distribuido el porcentaje de afiliados entre los cuatro fondos Porvenir, Protección, Colfondos y Old Mutual, como se puede evidenciar a continuación Porvenir posee 8’006.191 de afiliados, esto se debe a que dicho fondo no pone restricciones a la hora de aceptar afiliados, además, de ser el más renombre y recordación en el país.

Tabla 2. Número de afiliados actualmente en las Administradoras de Fondos de Pensiones (AFP)

\begin{tabular}{|c|c|c|}
\hline FONDO & \# AFILIADOS & PORCENTAJE \\
\hline PORVENIR & 8.006 .191 & $56,40 \%$ \\
\hline
\end{tabular}




\begin{tabular}{|c|c|c|}
\hline PROTECCIÓN & 1.842 .782 & $28,87 \%$ \\
\hline COLFONDOS & 105.826 & $12,98 \%$ \\
\hline OLD MUTUAL & 14.195 .547 & $0,75 \%$ \\
\hline
\end{tabular}

Fuente: Construcción propia en base a datos Porvenir (2017)

\subsection{PORTAFOLIOS EN COLOMBIA}

Actualmente, existen tres portafolios de inversión dentro de los fondos de pensión obligatoria en Colombia, según los tiempos productivos de las personas, con el fin de ser vehículos para el cumplimiento del capital de acceso a una pensión para los agentes.

Cada uno de estos portafolios, son estimados en valores de unidad que reflejan el comportamiento de cada uno de ellos dentro del portafolio. Dada la importancia de valoración y los impactos que han presentado las rupturas del mercado se hace indispensable buscar nuevas metodologías que aporten a los modelos tradicionales de portafolios eficientes, con lo cual se adquiere un entendimiento de los comportamientos de forma más estructurada y detallado de su desarrollo futuro.

Como se podrá, apreciar a lo largo del presente documento, la implementación del modelo de persistencia, el cual presenta diferentes dinámicas que muestran como una pequeña variación tiene repercusiones y efectos colaterales a futuro, lo cual, se convierte en una causa fundamental para llevar a cabo un análisis en términos financieros, teniendo en cuenta la importancia de los diferentes portafolios y perfiles de los usuarios, dado a las falencias que mantienen los mercados en términos de las incidencias que presentan a través del tiempo en los resultados finales de los portafolios. 
Por ello, la estructura de modelos de persistencia, permiten entender y complementar en términos del comportamiento de cada una de las variables analizadas, fundamentar y maximizar los resultados que se pueden obtener desde la administración de los activos.

A continuación, se puede encontrar una descripción de cada uno de los portafolios y sus características más sobresalientes, que ayudan a clasificar a las personas teniendo en cuenta variables como gusto, edad, pensión y/o necesidad, pero siempre dirigiéndose a la inversión y tolerancia al riesgo:

\section{PORTAFOLIO CONSERVADOR}

Este portafolio es creado, pensando en aquellas personas que se encuentran próximos a la edad de pensión, donde el fondo no realizara inversiones en títulos que tengan una gran exposición alta de riesgo, como es el caso de las acciones. Este perfil, evita a toda costa la exposición a riesgos elevados, conllevando, a sacrificar en múltiples ocasiones oportunidades de obtención de buenos rendimientos.

Se centra en invertir en promedio un $80 \%$ en fondos de mediano y largo plazo, mientras que un pequeño $20 \%$ se invierte en renta variable. (Treviño \& Garcias, 2013).

\section{PORTAFOLIO MODERADO}

Portafolio destinado para personas que se encuentran en una edad intermedia teniendo como referencia la edad de pensión, los cuales sean tolerantes a posiciones que tengan un riesgo no tan elevado/ medio. 
La inversión se distribuye aproximada entre un $60 \%$ en sociedades de deuda variable y el $40 \%$ restante es invertido en renta variable, llevando a lograr una rentabilidad mayor aunque se deba correr un poco más de riesgo. (Treviño \& Garcias, 2013)

\section{PORTAFOLIO AGRESIVO}

Este último portafolio, tiene como target principal los jóvenes, ya que se encuentren lejos de su edad de pensión, además, para aquellas personas que empiecen a trabajar y que su tolerancia al riesgo sea alta, siendo amantes al riesgo.

Para realizar inversiones en este portafolio, el riesgo es un factor completamente secundario, centrándose en el objetivo principal de obtener una rentabilidad elevada a cualquier costo. La composición de dicha cartera se realiza invirtiendo un $60 \%$ en renta variable, casi siempre representado en acciones muy volatines, y un $40 \%$ en fondos de deuda. (Treviño \& Garcias, 2013) 


\section{PERSISTENCIA Y COMPORTAMIENTOS IRREGULARES EN LOS MERCADOS}

El presente capitulo introduce a los diferentes conceptos y generalidades que determinan los estudios realizados por Mandebrot (1966), Hurst (1951), entre otros autores, encontrando evidencia de como las series de tiempo dentro del sistema financiero presentan un comportamiento que no concuerdan con los supuestos expuestos por Fama (1969), los cuales indica que un mercado cuenta con información completa.

Para ello, se abordarán definiciones de fractales, sus propiedades, los diferentes tipos que existen así, como su aplicación, para dar un mayor entendimiento al lector, acerca del contexto del surgimiento de como las estructuras estudiadas y vistas en la naturaleza, son relevantes para los diferentes estudios propuestos en el sistema financiero, siendo la fractalidad una de las condiciones iniciales para determinar estructuras persistentes dentro de los mercados de capitales.

Así mismo, se introduce el concepto de persistencia y series de tiempo de no normalidad, inicialmente estudiado por Hurst (1951), quien empezó a definir y determinar estructuras de comportamiento irregular, dentro de la medición de los niveles del Rio Nilo, concepto que se ha venido aplicando en los sistemas financieros.

Concluyendo que el proyecto se estructuró, a partir de las generalidades de comportamiento no normal dentro del sistema financiero y otras áreas del conocimiento. Así mismo, se recopilaron diversos estudios realizados y que han trabajado este tipo de 
fenómenos en diversas áreas y condiciones que son relevantes para la determinación de persistencia (pruebas de normalidad, persistencia, dimensionalidad, auto similitud, entre otros).

\subsection{FRACTALES}

Se puede inferir que una de las propiedades más importantes dentro del análisis de estructuras irregulares, es el concepto de fractales, el cual es entendido o definido por Mandelbrot (1983), como la descripción de aquellos objetos geométricos que presentan cierta inconsistencia dentro de su estructura y son considerados como irregulares, además se percibe que viene del concepto "fractus", que significa "roto", "fracturado" o "irregular".

La primera persona en acuñar el termino fractal en sus estudios fue Mandelbrot (1982), quien realizo la aplicación en diversas figuras geométricas. Adicionalmente, según Mandelbrot (1982) “Un fractal es por definición, un conjunto cuya dimensión de HausdorffBesicovitch es estrictamente mayor que su dimensión topológica"

Entendiendo lo anterior, podemos deducir que un fractal, es una figura geométrica que se presenta en la naturaleza, donde su estructura tiene diversas repeticiones a diferentes escalas. Las propiedades vistas en los fractales se definen como autosimilitud (como la condición de formación de escalas en figuras geométricas amplificadas, que son iguales a su original), autoafinidad o dimensionalidad; ejemplo de ello encontramos el triángulo de Serpinsky.

Por lo tanto podemos encontrar que una de las propiedad más relevante de los fractales es la autosimilitud, lo cual se interpretaba según las característica particulares o menores de una estructura geométrica, eran parecidas a su total, presentaban esta condición; 
esto entendido por Peters (1994) como una condición importante en el comportamiento de las series financieras alternando las frecuencias de los datos (periodicidad), podía medirse el nivel de riesgo de estos activos, dado a que el autor presumía que el supuesto de normalidad no se encuentra presente en todos os activos del sistema financiero.

Concluyendo, se pueden suponer diferentes características y tipos de fractales, que permiten entender lo definido por los autores, anteriormente mencionados. En la naturaleza existen dos tipos de fractales los cuales son lineales los cuales se pueden construir teniendo en cuenta un solo cambio dentro de la representación de las escalas, aquellos fractales son iguales en todas sus escalas, como se puede evidenciar a continuación:

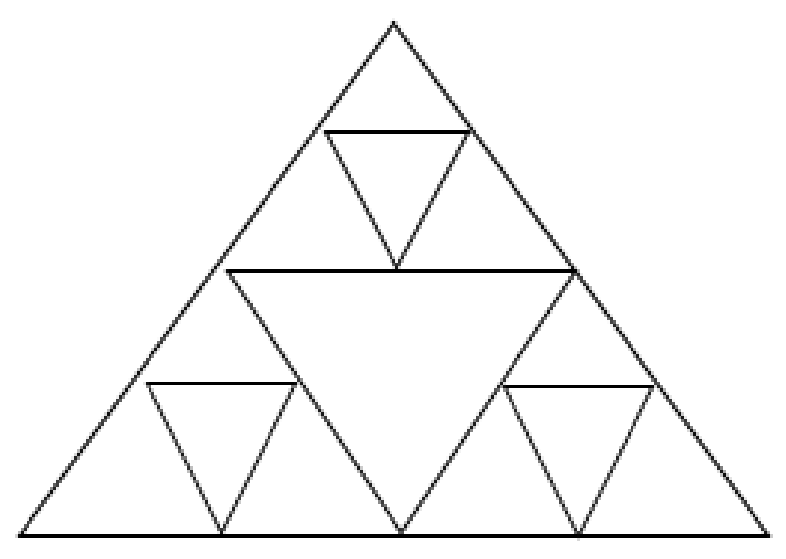

Fuente: Elaboración propia

No Lineales: Son aquellos que se generan a partir de distorsiones complejas o justamente como lo dice su nombre, usando un término proveniente de la matemática Caótica, distorsiones no lineales. La mayoría de los objetos fractales puramente matemáticos 
y naturales son no lineales. Ejemplos de ellos son: el reconocido Conjunto de Mandelbrot o el Conjunto de Julia.

Por lo tanto, se alusión a que muchos de los anteriores autores, refieren a un estudio más completo que puede ayudar a determinar un proceso más completo y complejo a la hora de evaluar fenómenos naturales, sociales, culturales y financieros, los cuales inician a ser fundamentales para el desarrollo del estudio de la estructura del comportamiento de los fondos de pensiones de la presente investigación. Por ello se presenta a continuación otra de las condiciones que se pueden evidenciar dentro del análisis de este tipo de estructuras, como es la persistencia y la metodología de cálculo de esta condición.

\subsection{CONDICIÓN DE PERSISTENCIA}

Una de las condiciones de los activos que no cuentan con los supuestos de normalidad es la persistencia, medida por la dependencia que tienen activos dentro de sus comportamiento, con respectos a sucesos que hayan ocurrido en el pasado, La metodología utilizada para determinar estructuras irregulares dentro de las series financieras, se evidencian dentro de lo expuesto por Velásquez \& Restrepo (2012), quien toma elementos relevantes y serán utilizados para este estudio, algunos de estos elementos son: Pruebas de Normalidad, Autosimilitud, Dimensión Fractal, persistencia a través del cálculo del exponente Hurst.

\section{NORMALIDAD}

La Ausencia de normalidad y no linealidad, son condiciones de estructuras de caos, por lo tanto, el primer paso será determinar la existencia de normalidad dentro de los retornos 
de los fondos de pensiones en Colombia, para ello se implementarán los test de Jarque-Bera, Shapiro-Wilk y Q-Q plot.

\section{TEST JARQUE - BERA}

Es una prueba que busca determinar si los datos que se están analizando tienen la curtosis condiciones de una distribución normal: El cual se define como:

$$
J B=\frac{n-k+1}{6}\left(S^{2}+\frac{1}{4}(c-3)^{2}\right)
$$

\section{TEST DE SHAPIRO - WILK}

Se utiliza para la comparación de comportamiento de normalidad dentro de los conjuntos de datos. Planteando la hipótesis de que los datos $x_{1} \ldots \ldots \ldots \ldots x_{n}$, vienen determinada por una población normalmente distribuida.

$$
W=\frac{\left(\sum_{i=1}^{n} a_{i} x_{(i)}\right)^{2}}{\sum_{i=1}^{n}\left(x_{(i)}-\bar{x}\right)^{2}}
$$

Donde:

$x_{(i)}$ : Numero que ocupa a i - enésima posición en la muestra.

$\bar{x}:$ Media muestral

Las variables $a_{1}$ se determinan a través de:

$$
\left(a_{1} \ldots, \ldots \ldots, a_{n}\right)=\frac{m^{T} V^{-1}}{\left(m^{T} V^{-1} V^{-1}\right)^{1 / 2}}
$$




\section{DIMENSIÓN FRACTAL}

El concepto de dimensión fractal se introduce respecto al hecho que la mayoría de los objetos de la naturaleza no tiene una dimensión entera, sino que están en una dimensión fraccionada y esta dimensión debe ser mayor que su dimensión topológica. Por esto, la dimensión fractal en sentido genérico es el número que sirve para cuantificar el grado de irregularidad y fragmentación de un conjunto geométrico o de un objeto natural. El exponente de Hurst está relacionado con la dimensión fractal D, de la siguiente manera: (i) para perfiles, para superficies y para volúmenes:

Son indicadores de autosimilitud estadística; se calculará a partir del exponente de Hurst, y estará determinado entre 1 y 2.

La dimensión fractal de una serie financiera brinda una visión más realista del riesgo que la varianza del activo (Casparri y Moreno, 2008), esto se debe a la no-normalidad que en general presenta la distribución de los activos financieros (Peters, 1991).

El cálculo para la dimensión fractal se estima, a través del cálculo de la diferencia entre el Exponente de Hurst y la dimensión:

$$
D=\frac{\log N}{\log \frac{1}{r}}=\lim _{r \rightarrow 0}-\frac{\log N}{\log r}
$$

Persistencia: La relación de memoria en una serie y la capacidad de seguir un comportamiento de tendencia a largo plazo se denomina persistencia, lo cual ocurre cuando los sucesos actuales pueden incidir en los resultados futuros de la serie. 
Los modelos de persistencia que pueden ser usados para el cálculo de persistencia se representa a continuación:

\section{ANÁLISIS POR COMPONENTES PRINCIPALES (PCA)}

La estimación a través de componentes principales se realiza a través de una transformación lineal, buscando determinar un sistema de coordenadas a partir del conjunto original de datos.

El objetivo es transformar un conjunto dado de $\mathrm{X}$ datos con dimensiones $\mathrm{n} \times \mathrm{m}$, a otro conjunto de datos de menor dimensión $\mathrm{n}$ x 1, con la menor pérdida posible de cantidad de información útil haciendo uso de la matriz de covarianza.

$$
\operatorname{COV}\left(S_{x y}\right)=\frac{1}{N-1} \sum_{n=1}^{N}[(x(n)-\bar{X})(y(n)-\bar{Y})]
$$

\section{MODELO DE RANGO REESCALADO (R/S)}

“El análisis de persistencia de las series se hace por medio del exponente de Hurst. Existen varios métodos para calcular este exponente; aquí se emplea el método de ReEscalonamiento (R/S), desarrollado por Hurst (1951) que permite determinar la dependencia de largo plazo de la serie"

$$
\ln \left(\frac{R}{S}\right)==\operatorname{Ln}(A)+H * \operatorname{Ln}(n)+\epsilon
$$

1. $\operatorname{Ln}(\mathrm{a})$ es igual al valor de intercepto. 
2. Ln (n) Logaritno natural de los periodos por cada partición.

3. H es la pendiente del modelo y el exponente de Hurst.

\subsection{METODOLOGÍA}

Se tomaron como base 7 mil datos que representan la muestra de los valores de unidad de un fondo de pensiones en Colombia, tomando un periodo de 2010- 2016 para cada uno de los portafolios (conservador, moderado y agresivo). Los cuáles serán analizados con el fin de poder reducir la asimetría de información con respecto al comportamiento de los fondos de pensiones en Colombia, a partir del análisis de persistencia y la ley 1328 de 2009.

Por ello, se aplicará el cálculo del exponente de Hurst, la cual, es una técnica utilizada para el análisis de comportamiento de persistencia, teniendo como variable principal el tiempo. Fue expuesta por el hidrólogo Hurst (1951), quien realizo una investigación acerca de la fluctuación de los niveles del rio Nilo, con el fin de determinar comportamientos de tipo fractal en este tipo de series, creando un modelo que permite identificar si la existencia de comportamientos en T-1 (pasado), influyen en los resultados de $\mathrm{T}+1$ (futuro). El exponente puede ser calculado a través de la metodología de Rango Reescalado (R/S), expuesto por Mandelbrot (1966), para llevar a cabo el cálculo de este exponente se deben realizar los siguientes pasos:

a. Fraccionar los datos, es decir formar series con datos más pequeños. Para este trabajo se realizarán 6 particiones, con conjunto de datos de 10, 50, 100, 500, 1000 y 1751 días.

b. Determinar a partir de la fórmula de promedio simple $\bar{X}=\sum \frac{X i}{n}$, donde $X i$, el valor de unidad diario y n será el número de días tomados en cada participación. La 
desviación de la media (excesos de retorno), con respecto a cada dato $E \cdot R=X i-\bar{X}$ y la desviación estándar $\sigma=\sqrt{\frac{(X i-X)^{2}}{n}}$, para cada partición.

c. Determinar el rango para cada partición: $R=\operatorname{Max}-\operatorname{Min}$

d. Construir una tabla que represente el $\operatorname{Ln}(\mathrm{n})$ y el $\operatorname{Ln}(\mathrm{R} / \mathrm{S})$, donde $\mathrm{R}=$ Rango y $\mathrm{S}=$ desviación estándar.

e. Determinar a través de un modelo de regresión. La pendiente encontrada será definida como el exponente de Hurst.

$$
\operatorname{Ln}\left(\frac{R}{S}\right)=\operatorname{Ln}(A)+H * \operatorname{Ln}(n)+\epsilon
$$

- $\operatorname{Ln}(a)$ es igual al valor de intercepto.

- Ln (n) Logaritno natural de los periodos por cada partición.

- H es la pendiente del modelo y el exponente de Hurst.

Con respecto al modelo planteado anteriormente, se expone en la tabla 3 la interpretación según los parámetros de análisis para el exponente de Hurst, descritos por Carr (1997):

Tabla 3. Interpretación del modelo de Rango Reescalado (R/S)

\begin{tabular}{|l|l|}
\hline Rango & Interpretación \\
\hline & Comportamiento antiperistente. Lo que \\
& quiere decir es que un evento del pasado \\
& supone una caída en los resultados futuros. \\
\hline
\end{tabular}




\begin{tabular}{|l|l|}
\hline $0.5<\mathrm{H}<1$ & $\begin{array}{l}\mathrm{H}=0, \text { corresponde a ruido blanco. Significa } \\
\text { que es ruido blanco. }\end{array}$ \\
\hline Comportamiento determinista. Ruido \\
negro, y es que existe una relación en los \\
procesos cíclicos a largo plazo. Es decir, \\
todos los comportamientos actuales, tienen \\
incidencia sobre los resultados futuros. \\
\hline $\mathrm{H}=1$ & $\begin{array}{l}\text { Tienen incidencia en los resultados futuros } \\
\text { los eventos pasados, están relacionados con } \\
\text { los comportamientos en precios de la bolsa } \\
\text { de valores y los caudales de los ríos. }\end{array}$ \\
\hline
\end{tabular}

Fuente: Carr (1997) 


\section{ESTIMACIONES DE PERSISTENCIA}

En el tercer capítulo se desarrollara la aplicación de la metodología de Rango Reescaaldo (R/S) y Exponente de Hurst, sobre los portafolios de inversión en los fondos de pensiones en Colombia (conservador, moderado y agresivo), con el fin, de estimar si existe persistencia dentro del comportamiento de los valores de unidad de estas series en un periodo del año 2010 al 2016, complementando así, los estudios de mercados eficientes en el sector financiero y ampliando los modelos que pueden ser aplicables a este tipo de estructuras.

Loa anterior permite reducir asimetría de información y aportando a la mejor administración de estos fondos. Se encuentra que para los tres portafolios los exponentes $\mathrm{H}$ (Hurst), son mayores que 0,5 , lo cual reitera la justificación y el problema de investigación, que este tipo de estructuras no se comporta como una distribución normal y se puede llevar a realizar la aplicación de otros modelos, complementando los que ya existen.

\subsection{APLICACIÓN DEL MODELO DE RANGO REESCALADO (R/S)}

Las siguientes estimaciones fueron elaboradas a partir de valores de unidad de cada uno de los portafolios de un fondo de pensiones en Colombia, desde el año 2010 hasta el año 2016. En el eje X están las fechas de valoración y en el eje Y los resultados de los valores de unidad.

Pasos para la construcción del modelo para cada uno de los portafolios: 
a. Fraccionar los datos, es decir formar series con datos más pequeños. Para este trabajo se realizarán 6 particiones, con conjunto de datos de 10, 50, 100, 500, 1000 y 1751 días, para los datos del portafolio agresivo.

b. Determinar a partir de la fórmula de promedio simple $\bar{X}=\sum \frac{X i}{n}$, donde $X i$, el valor de unidad diario y n será el número de días tomados en cada participación. La desviación de la media (excesos de retorno), con respecto a cada dato $E . R=X i-\bar{X}$ y la desviación estándar $\sigma=\sqrt{\frac{(X i-X)^{2}}{n}}$, para cada partición, para los datos del portafolio agresivo.

c. Determinar el rango para cada partición: $R=\operatorname{Max}-\operatorname{Min}$, para los datos del portafolio agresivo.

d. Construir una tabla que represente el $\operatorname{Ln}(n)$ y el $\operatorname{Ln}(\mathrm{R} / \mathrm{S})$, donde $\mathrm{R}=$ Rango y $\mathrm{S}=$ desviación estándar, para los datos del portafolio agresivo.

A continuación, se presentan las estimaciones y pruebas de persistencia a partir de la metodología de Rango Reescalado (R/S) en los 3 portafolios de inversión que existen actualmente en el sistema pensional en Colombia, a partir de la ley 1328 de 2009.

\subsubsection{PORTAFOLIO CONSERVADOR}

Portafolio Conservador: Portafolio con volatilidad baja en el tiempo, y porcentaje menor de rentabilidad y apto para aquellas personas que tienen una condición de aversión al riesgo.

A continuación, en el grafico 1 se puede observar el comportamiento de los valores de unidad del portafolio conservador, para los últimos 5 años, con una temporalidad diaria, mostrando que, para este periodo de tiempo, ha tenido un crecimiento importante con 
respecto a su valor nominal, con un crecimiento estable según lo establecido por la Superintendencia Financiera.

Grafico 1: Serie de comportamiento Portafolio conservador 2010 - 2016

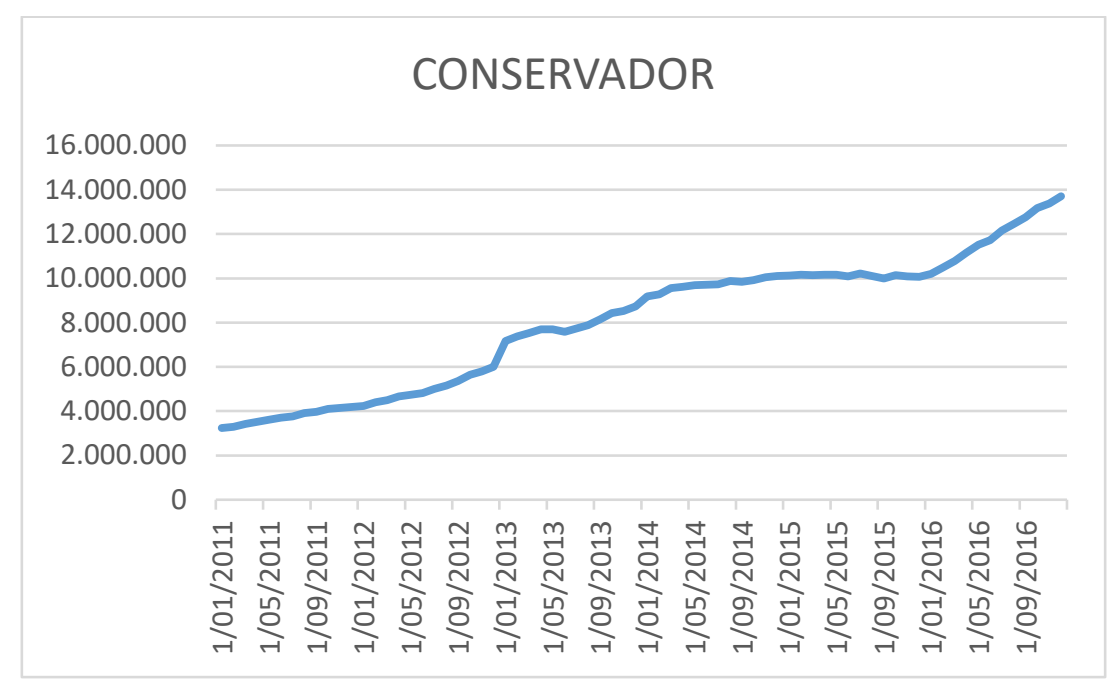

Fuente: Elaboración propia con base a datos de valor del fondo de la Superfinanciera

El grafico anterior muestra un crecimiento del portafolio conservador para los últimos 5 años, mostrando una valorización del valor de unidad desde \$2`000.000 hasta \$14’000.000 aproximadamente, lo cual representa una variación porcentual del 45\% y un promedio de rentabilidad de $38 \%$ E.A.

A continuación, se presenta en la tabla 4, los resultados obtenidos de las estadísticas descriptivas y los datos fraccionados, descritos en la metodología, por ello se presentan a continuación los pasos para su construcción.

La siguiente tabla se construye a través de los pasos mencionados a continuación: 
a. Fraccionar los datos, es decir formar series con datos más pequeños. Para este trabajo se realizarán 6 particiones, con conjunto de datos de 10, 50, 100, 500, 1000 y 1751 días, para los datos del portafolio conservador.

b. Determinar a partir de la fórmula de promedio simple $\bar{X}=\sum \frac{X i}{n}$, donde $X i$, el valor de unidad diario y n será el número de días tomados en cada participación. La desviación de la media (excesos de retorno), con respecto a cada dato $E . R=X i-\bar{X}$ y la desviación estándar $\sigma=\sqrt{\frac{(X i-X)^{2}}{n}}$, para cada partición, para los datos del portafolio conservador

c. Determinar el rango para cada partición: $R=$ Max - Min para los datos del portafolio conservador

d. Construir una tabla que represente el $\operatorname{Ln}(n)$ y el $\operatorname{Ln}(\mathrm{R} / \mathrm{S})$, donde $\mathrm{R}=$ Rango y $\mathrm{S}=$ desviación estándar, para los datos del portafolio agresivo.

Tabla 4: Serie de datos metodología de R/S portafolio conservador

\begin{tabular}{|c|c|c|c|c|c|}
\hline $\mathbf{N}$ & $\mathbf{R}$ & $\mathbf{S}$ & $\mathbf{R} / \mathbf{S}$ & $\mathbf{L N ~ N}$ & $\mathbf{L N ~ R / S}$ \\
\hline $\mathbf{1 0}$ & 0,002 & 0,001 & 2,736 & 2,303 & 1,007 \\
\hline $\mathbf{5 0}$ & 0,008 & 0,001 & 5,903 & 3,912 & 1,775 \\
\hline $\mathbf{1 0 0}$ & 0,014 & 0,014 & 1,000 & 4,605 & - \\
\hline $\mathbf{5 0 0}$ & 0,031 & 0,031 & 1,000 & 6,215 & - \\
\hline $\mathbf{1 0 0 0}$ & 0,111 & 0,002 & 67,234 & 6,908 & 4,208 \\
\hline $\mathbf{1 7 5 1}$ & 0,111 & 0,002 & 69,260 & 7,468 & 4,238 \\
\hline
\end{tabular}

Fuente: Elaboración propia con base a datos de valor del fondo de la Superfinanciera

En el grafico 2 determinamos el modelo de regresión. Que permite determinar el valor del exponente de Hurst. 
Grafico 2: Estimación del Exponente de Hurst modelo de regresión lineal - portafolio conservador.

Se corre el modelo de regresión, teniendo en cuenta las variables LN (N) y LN (R/S).

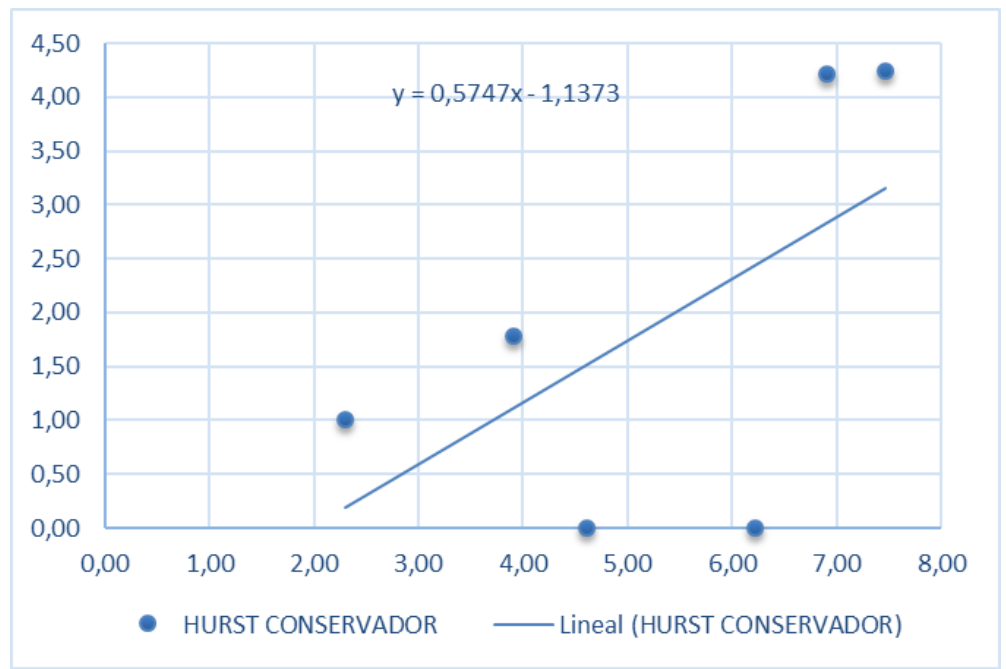

Fuente: Elaboración propia con base a datos de valor del fondo de la Superfinanciera

Modelo de (R/S)

$$
\ln \left(\frac{R}{S}\right)==1,1373+0,5747 * \operatorname{Ln}(n)
$$

Se observa que el exponente de Hurst es igual a 0,5747 lo cual muestra que no presenta un comportamiento normal en las series. Pudiendo definir de esta manera, que parte de los resultados futuros, tienen una probabilidad de ser influenciados por los eventos del pasado.

\subsubsection{PORTAFOLIO MODERADO}

Portafolio Moderado: Portafolio con un grado de volatilidad media a través del tiempo, baja rentabilidad y se considera para aquellas personas que son neutras al riesgo. 
Grafico 3: Serie de comportamiento Portafolio moderado 2010 - 2016

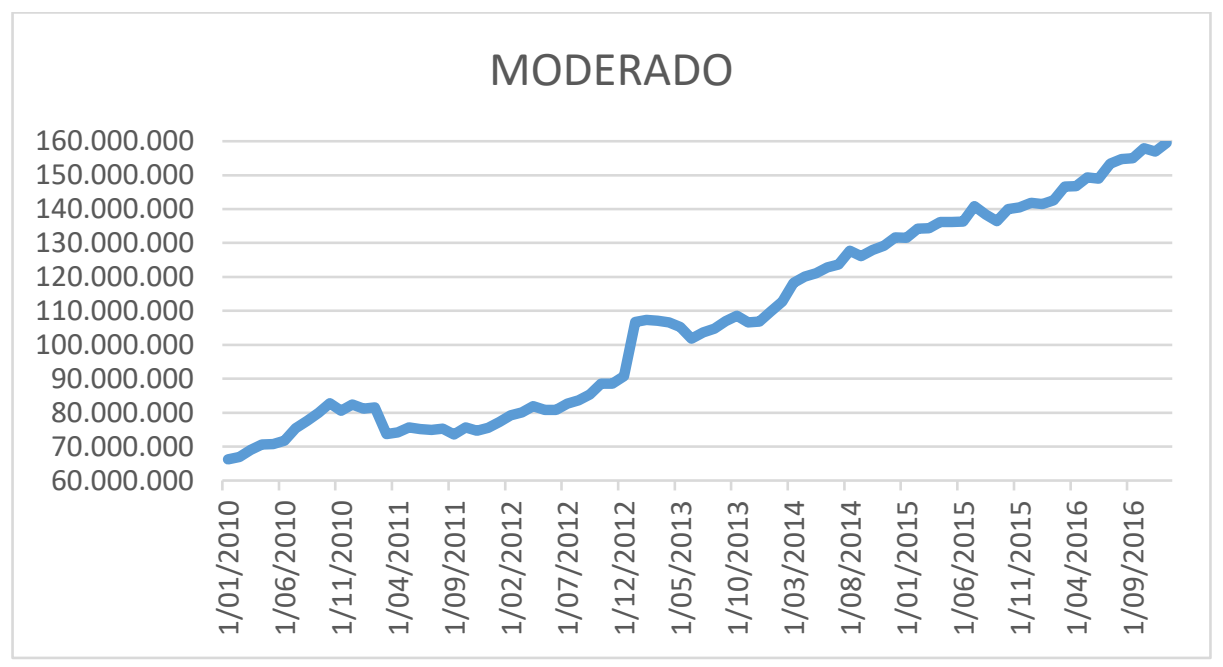

Fuente: Elaboración propia con base a datos de valor del fondo de la Superfinanciera

El grafico anterior muestra un crecimiento del portafolio conservador para los últimos 5 años, mostrando una valorización del valor de unidad desde $\$ 65^{\prime} 000.000$ hasta $\$ 160 ` 000.000$ aproximadamente, lo cual representa una variación porcentual del 40\% y un promedio de rentabilidad de $16,99 \%$ E.A.

\section{La siguiente tabla se construye a través de los pasos mencionados a continuación:}

a. Fraccionar los datos, es decir formar series con datos más pequeños. Para este trabajo se realizarán 6 particiones, con conjunto de datos de 10, 50, 100, 500, 1000 y 1751 días, para los datos del portafolio moderado.

b. Determinar a partir de la fórmula de promedio simple $\bar{X}=\sum \frac{X i}{n}$, donde $X i$, el valor de unidad diario y $\mathrm{n}$ será el número de días tomados en cada participación. La desviación de la media (excesos de retorno), con respecto a cada dato $E . R=X i-\bar{X}$ 
y la desviación estándar $\sigma=\sqrt{\frac{(X i-X)^{2}}{n}}$, para cada partición, , para los datos del portafolio moderado.

c. Determinar el rango para cada partición: $R=$ Max - Min , para los datos del portafolio moderado.

d. Construir una tabla que represente el $\operatorname{Ln}(n)$ y el $\operatorname{Ln}(\mathrm{R} / \mathrm{S})$, donde $\mathrm{R}=$ Rango y $\mathrm{S}=$ desviación estándar, para los datos del portafolio moderado.

Tabla 5: Serie de datos metodología de R/S portafolio moderado

\begin{tabular}{|c|c|c|c|c|c|}
\hline $\mathbf{N}$ & $\mathbf{R}$ & $\mathbf{S}$ & $\mathbf{R} / \mathbf{S}$ & $\mathbf{L N ~ N}$ & $\mathbf{L N} \mathbf{R} / \mathbf{S}$ \\
\hline $\mathbf{1 0}$ & 0,005 & 0,002 & 2,930 & 2,303 & 1,075 \\
\hline $\mathbf{5 0}$ & 0,014 & 0,002 & 6,211 & 3,912 & 1,826 \\
\hline $\mathbf{1 0 0}$ & 0,029 & 0,029 & 1,000 & 4,605 & - \\
\hline $\mathbf{5 0 0}$ & 0,082 & 0,082 & 1,000 & 6,215 & - \\
\hline $\mathbf{1 0 0 0}$ & 0,157 & 0,003 & 53,359 & 6,908 & 3,977 \\
\hline $\mathbf{1 7 5 1}$ & 0,133 & 0,003 & 45,250 & 7,468 & 3,812 \\
\hline
\end{tabular}

Fuente: Elaboración propia

Grafico 4: Estimación del Exponente de Hurst modelo de regresión lineal - portafolio moderado.

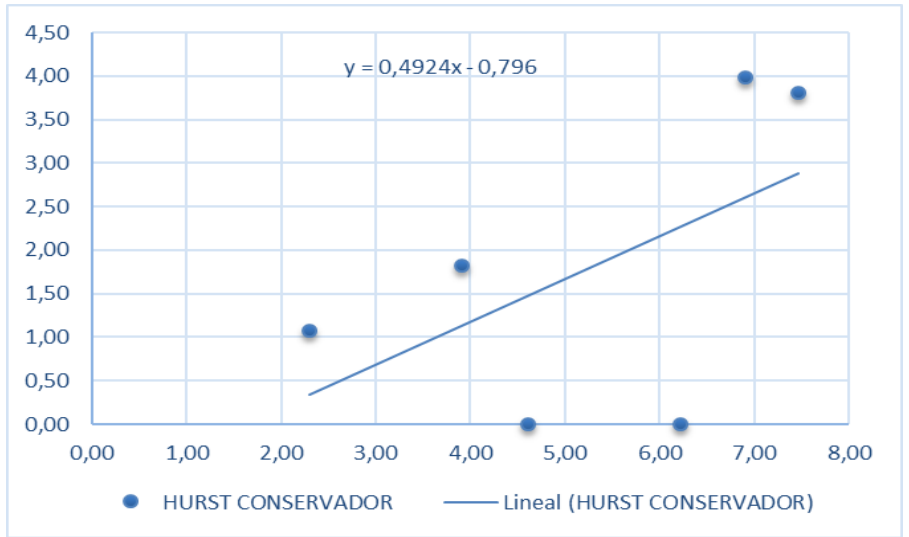

Fuente: Elaboración propia 


$$
\ln \left(\frac{R}{S}\right)==0,796+0,4924 * \operatorname{Ln}(n)
$$

Se observa que el exponente de Hurst es igual a 0,4924 lo cual muestra que no presenta un comportamiento normal en las series. Pudiendo definir que parte de los resultados futuros, tienen una probabilidad de ser influenciados de forma inversa por los eventos del pasado.

\subsubsection{PORTAFOLIO AGRESIVO}

Portafolio Agresivo: Portafolio con un grado de volatilidad alta a través del tiempo, con aumento significativa rentabilidad y puede considerarse para aquellas personas que son amantes al riesgo.

\section{Grafico 5: Serie de comportamiento Portafolio agresivo 2010 - 2016}

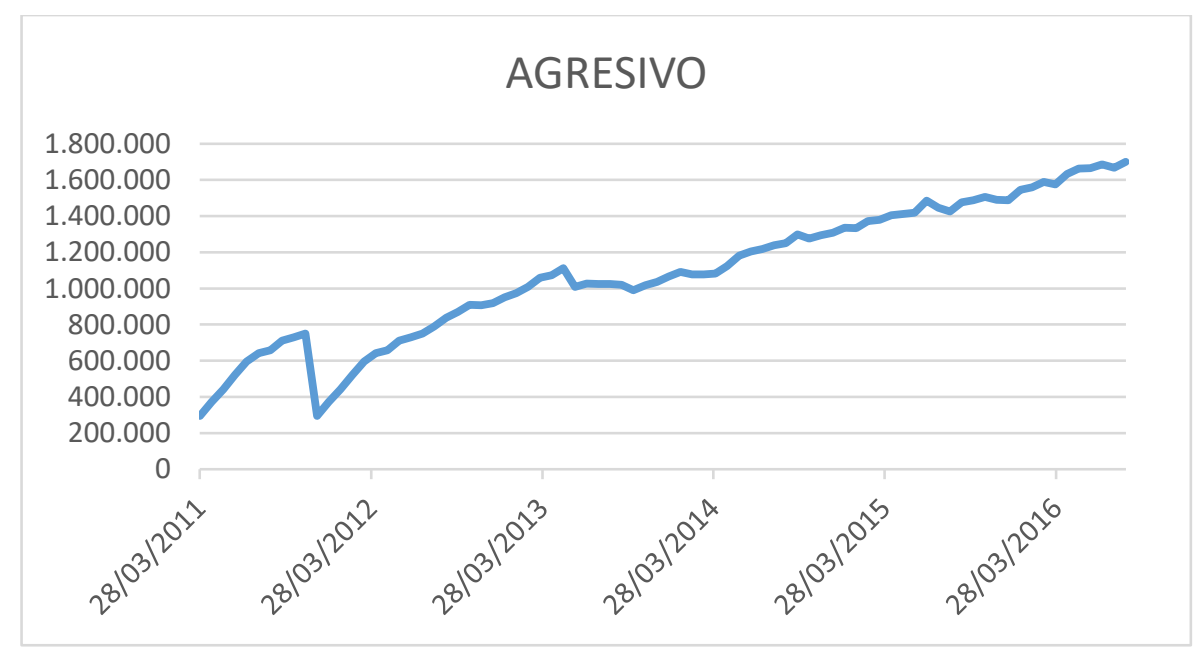

Fuente: Elaboración propia con base a datos de valor del fondo de la Superfinanciera

El grafico anterior muestra el comportamiento del portafolio agresivo, presentando un crecimiento, a pesar de las variaciones negativas que ha presentado del portafolio 
conservador para los últimos 5 años, mostrando una valorización del valor de unidad desde \$20.000 hasta \$27.000 aproximadamente, lo cual representa una variación porcentual del $35 \%$ y un promedio de rentabilidad de $41,42 \%$ E.A.

a. Fraccionar los datos, es decir formar series con datos más pequeños. Para este trabajo se realizarán 6 particiones, con conjunto de datos de 10, 50, 100, 500, 1000 y 1751 días, para los datos del portafolio agresivo.

b. Determinar a partir de la fórmula de promedio simple $\bar{X}=\sum \frac{X i}{n}$, donde $X i$, el valor de unidad diario y n será el número de días tomados en cada participación. La desviación de la media (excesos de retorno), con respecto a cada dato $E \cdot R=$ $X i-\bar{X}$ y la desviación estándar $\sigma=\sqrt{\frac{(X i-X)^{2}}{n}}$, para cada partición, , para los datos del portafolio agresivo.

c. Determinar el rango para cada partición: $R=\operatorname{Max}-\operatorname{Min}$, para los datos del portafolio agresivo.

d. Construir una tabla que represente el $\operatorname{Ln}(n)$ y el $\operatorname{Ln}(\mathrm{R} / \mathrm{S})$, donde $\mathrm{R}=$ Rango y $\mathrm{S}=$ desviación estándar, para los datos del portafolio agresivo.

Tabla 6: Serie de datos metodología de R/S portafolio agresivo

\begin{tabular}{|c|c|c|c|c|c|}
\hline $\mathbf{N}$ & $\mathbf{R}$ & $\mathbf{S}$ & $\mathbf{R} / \mathbf{S}$ & $\mathbf{L N} \mathbf{N}$ & $\mathbf{L N} \mathbf{R} / \mathbf{S}$ \\
\hline $\mathbf{1 0}$ & 0,004 & 0,001 & 2,656 & 2,303 & 0,977 \\
\hline $\mathbf{5 0}$ & 0,025 & 0,003 & 7,323 & 3,912 & 1,991 \\
\hline $\mathbf{1 0 0}$ & 0,029 & 0,003 & 9,716 & 4,605 & 2,274 \\
\hline $\mathbf{5 0 0}$ & 0,110 & 0,004 & 26,739 & 6,215 & 3,286 \\
\hline $\mathbf{1 0 0 0}$ & 0,190 & 0,004 & 49,256 & 6,908 & 3,897 \\
\hline $\mathbf{1 7 5 1}$ & 0,156 & 0,004 & 37,920 & 7,468 & 3,635 \\
\hline
\end{tabular}

Fuente: Elaboración propia con base a datos de valor del fondo de la Superfinanciera 
Grafico 6: Estimación del Exponente de Hurst modelo de regresión lineal - portafolio agresivo

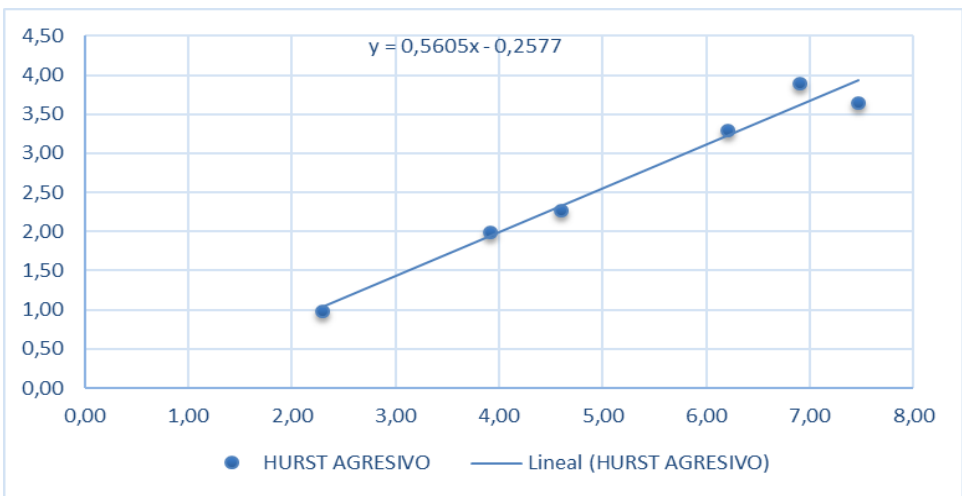

Fuente: Elaboración propia con base a datos de valor del fondo de la Superfinanciera

El grafico representa una regresión lineal, la cual presenta el modelo de Rango Reescalado (R/S).

Modelo de Rango Reescalado (R/S)

$$
\ln \left(\frac{R}{S}\right)==0,2577+0,5605 * \operatorname{Ln}(n)
$$

Se observa que el exponente de Hurst es igual a 0,5605 lo cual muestra que no presenta un comportamiento normal en las series. Pudiendo definir que parte de los resultados futuros, tienen una probabilidad de ser influenciados por los eventos del pasado. 


\section{EVALUACIÓN DE LA LEY 1328 DE}

2009

El presente capitulo busca complementar los hallazgos encontrados en el capítulo 3, evidenciando que existen nuevas propuestas que pueden llegar a reducir la asimetría de información por parte de los agentes de mercado. Encontrando, que a partir de los 3 portafolios que existen actualmente en los fondos de pensiones en Colombia, se esconde información que puede llevar a tomar mejores decisiones.

En el desarrollo de este capítulo calcularemos la mesada pensional bajo dos rangos de edad 20 -30 años y 30 - 40 años, teniendo como base los datos relevantes como el ingreso, el portafolio, ahorro en la cuenta individual y el tiempo para pensionarse, encontrando que existen diferencias sustanciales entre los esquemas de estar invertidos en un solo portafolio vs a utilizar el esquema de multifondos, que ayuda a maximizar el capital a la hora de pensionarse.

Además, se encontró que las brechas de ingreso por persona y las diferenciales salariales entre hombres y mujeres, pueden resolverse con políticas de ahorro y estructuración de la edad de pensión. Adicionalmente, se encontró que se puede descongestionar el Régimen De Prima Media (RPM), bajo el esquema de los fondos privados, con el fin, que el estado solo se encargue de subsidiar aquellas personas que no tienen la posibilidad económica de acceder a una pensión; respondiendo de igual forma a la reducción de la información, acerca de cuál puede ser la mesada pensional de las personas a futuro, la reestructuración del sistema y el funcionamiento del mismo, apoyando a resolver los problemas de investigación planteados en este trabajo. 


\subsection{MODELO TEORICO}

Para el cálculo de la mesada pensional en el RAIS, se deben tener en cuenta variables como el ahorro individual alcanzado, la esperanza de vida del mismo y el grupo familiar, rentabilidad, crecimiento de la pensión, gastos de administración posteriores a la pensión. Este cálculo se basa en las disposiciones contenidas en la Resolución 3099 de 2015. Esta metodología se puede expresar como:

$$
\operatorname{SPM}(s)=\frac{V A\left[\left(S M M, \Omega(X, Y, \ldots), r, f, \Delta, \mu, T M^{\Omega}, S\right]+A F(S M M, x, r, f)\right.}{(1-g)}
$$

Donde:

S: Mes de cálculo, s = 1, 2, 3, ..., 11. Asignando los números de la siguiente forma:

0 en 1 enero (31 de diciembre año anterior)

1 en 1 febrero (31 de enero)

11 en 1 diciembre (30 de noviembre)

VA: Valor presente actuarial, de una renta vitalicia para el causante o sus beneficiarios

AF. Valor presente actuarial, por concepto de auxilio funerario.

SMM: Valor en pesos de un salario mínimo mensual vigente, al momento del cálculo. 


\subsection{CONDICIONES DE AHORRO}

\section{BARRERAS PARA EL AHORRO DE LARGO PLAZO}

Las siguientes proyecciones se estiman teniendo como base la necesidad que las personas comprendan cómo funcionan los fondos de pensiones, en términos de los resultados que pueden obtener en las mesadas pensionales y como poder maximizar su beneficio a través de la etapa de ahorro. Esperando, tener un mejor capital en el futuro y no enfrentarse a los factores de pobreza que se generan por los altos costos de salud en personas de edad adulta.

\section{ETAPA DE ACUMULACIÓN DEL AHORRO}

La etapa de ahorro para las personas se interrumpe desde el momento en que empiezan a trabajar, dado que no le prestan atención a las necesidades futuras que tendrán, como lo es la pensión medida en términos de calidad de vida. Lo cual muestra un problema en el sistema de la baja acumulación de capitales por parte de las personas, en busca de que el estado subsidie la diferencia entre lo ahorrado y lo necesario para obtener una pensión.

A continuación, se revisa como se entiende la concepción de ahorro desde el punto de vista teórico de la hipótesis del ciclo de vida expuesto por Modigliani Y Brumber (1954), Quien plantea que, a lo largo de la vida, los individuos tienen una etapa de acumulación de dinero, que se obtiene a partir de la renta adquirida, con la expectativa de que en la etapa de jubilación obtenga un consumo superior a su renta adquirida en su etapa laboral.

Además, plantea que los individuos consumirán el total de su riqueza a lo largo de su vida, como sus bienes, patrimonio entre otros, teniendo como suposición que el individuo no dejara deudas, lo cual según la renta obtenida en su etapa laboral se verá reflejada en la 
cantidad de recursos que logre acumular en su etapa productiva y la proporción que obtenga en los años que desahorrará sus recursos (pensión).

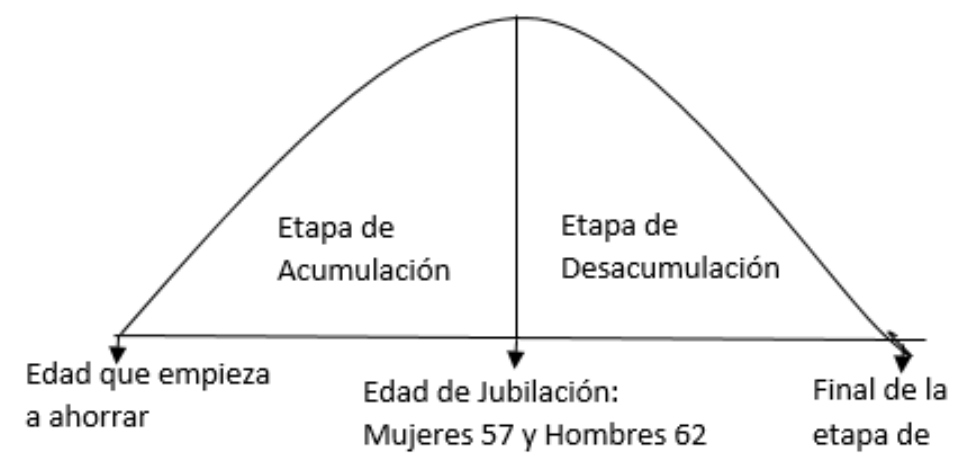

\section{Fuente: Elaboración propia}

En el grafico anterior se muestra, desde una perspectiva sencilla como es la acumulación y desacumulación del dinero en la etapa de producción de las personas en base a los salarios que pueden obtener en su etapa productiva, tal como lo menciona Friedman (1957) en su teoría de la renta permanente. Claramente dentro del aspecto colombiano se muestran muchos de los problemas que intervienen en la intención de ahorro de las personas, las cuales se pueden observar desde dos puntos de vista:

\section{Demanda}

- Altos costos de Transacción (Cobros)

- Brechas de Información y conocimiento

- Restricciones del comportamiento

- Peticiones Sociales

- Falta de Confianza

\section{Oferta}


- Barreras regulatorias (Acceso al sistema financiero)

- Rentabilidad/Costos de transacción

Una de las variables que inciden en que las personas no ahorren a largo plazo, es el desconocimiento de cómo funcionan aquellas alternativas que pueden ayudar a incrementar su capital, asegurando una calidad de vida mejor en el largo plazo, como decía Kiyosaky (2000) "Los problemas financieros de una persona no es por falta de dinero, sino de educación financiera". Lo anterior, nos lleva a brindar la mayor información posibles a los agentes de mercado que buscan maximizar sus funciones de utilidad, donde ambas partes salgan beneficiados. Por ello es de suma importancia que las personas conozcan cómo puede ser su futuro pensional, para tomar las medidas correctivas con tiempo y poder disfrutar de una vejez digna.

Las siguientes simulaciones se basan en dos escenarios según rangos de edad: 20 30 años y $31-40$ años. Con supuestos de inflación estimados a partir de las proyecciones que tenía el Banco de la república para el año 2016 entre el 2\% - 4\%. Tomando como base el 4\%, para el crecimiento del salario mínimo en los próximos años y el aumento en el coste de vida de las personas.

\subsubsection{PRIMER ESCENARIO}

\section{HOMBRES: RANGO DE EDAD 20 -30 AÑOS}

Simulación con base en un promedio según el rango de cotización de una persona que en promedio tiene 25 años. 
El incremento del SMMLV para todos los escenarios están atados a una tasa de inflación del 4\% E.A. Los aportes al fondo de pensiones son el 11\% que se destina a la cuenta individual de los afiliados. Los 10 años se toman con base en que la persona inicie una cotizacion al sistema a partir de los 20 años.

Tabla 7: Estimación del salario mínimo en 10 años.

\begin{tabular}{|c|cc|cr|}
\hline PERIODO & \multicolumn{2}{|c|}{ INGRESO } & \multicolumn{2}{c|}{ APORTE A ISS } \\
\hline AÑO 1 & $\$ 737.717$ & $\$$ & 81.149 \\
\hline AÑO 2 & $\$$ & 767.226 & $\$$ & 84.395 \\
\hline AÑO 3 & $\$$ & 797.915 & $\$$ & 87.771 \\
\hline AÑO 4 & $\$$ & 829.831 & $\$$ & 91.281 \\
\hline AÑO 5 & $\$$ & 863.025 & $\$$ & 94.933 \\
\hline AÑO 6 & $\$$ & 897.546 & $\$$ & 98.730 \\
\hline AÑO 7 & $\$$ & 933.447 & $\$$ & 102.679 \\
\hline AÑO 8 & $\$$ & 970.785 & $\$$ & 106.786 \\
\hline AÑO 9 & \$1.009.617 & $\$$ & 111.058 \\
\hline AÑO 10 & \$1.050.001 & $\$$ & 115.500 \\
\hline
\end{tabular}

\section{Fuente: Elaboración propia}

\section{Las variables que se tomaran en cuenta:}

Dentro de la determinación del modelo de mesada pensional dentro del régimen de prima media (RPM), será igual al ingreso base de liquidación, el cual se multiplica por un porcentaje de IBL. La fórmula de cálculo es:

$$
\mathrm{r}=65,5 \%-0,5^{*} \mathrm{~s}
$$

$\mathrm{s}=$ Salarios mínimos legales vigentes

La dinámica de esta fórmula permite que la relación con respecto al ingreso se decreciente, dado que se busca darles un mayor porcentaje a las personas con ingresos más bajos. 
Dentro del régimen de ahorro individual entre más alto sea el capital conformado al momento de la pensión. Este capital acumulado se compone del saldo en la cuenta individual con los rendimientos generados, por el periodo de cotización, el bono pensional si tiene derecho y si existe algún tipo de aportes voluntarios, para ello las variables tomadas en cuenta para el cálculo de mesada pensional:

- Ingreso: Los datos fueron tomados desde un salario hasta 8 salarios mínimos. Multiplicando el valor inicial por la cantidad de salarios.

- Semanas cotizadas 1994: Se asumen 0 semanas, porque son personas que nacieron entre los años 80 y 90, por lo cual no ejercen como afiliados al sistema en este año.

- Semanas cotizadas: Se consideraron 260 semanas con una confiabilidad del $50 \%$ de aportes al sistema, dado que pueden pasar que la persona quede cesante por algunos meses y no pueda aportar al sistema.

- Capital en cuenta individual: Se lleva a Valor futuro del valor del aporte mensual durante los 10 años. Teniendo en cuenta la capitalización mensual de los aportes.

Tabla 8: Variables a considerar en el cálculo de la mesada pensional edad 20 - 30 años

\begin{tabular}{|cc|c|cc|}
\hline \multicolumn{5}{|c|}{ EDAD 20 A 30 AÑOS } \\
\hline & & $\begin{array}{c}\text { SEMANAS } \\
\text { COTIZADAS A } \\
\text { REGIMEN DE } \\
\text { INGRESO } \\
\text { INDIVIDU }\end{array}$ & $\begin{array}{c}\text { CAPITAL EN CUENTA } \\
\text { INDIVIDUAL }\end{array}$ \\
\hline$\$$ & 737.717 & 260 & $\$$ & 16.001 .875 \\
\hline$\$$ & 1.475 .434 & 260 & $\$$ & 32.003 .749 \\
\hline$\$$ & 2.213 .151 & 260 & $\$$ & 48.005 .624 \\
\hline$\$$ & 2.950 .868 & 260 & $\$$ & 64.007 .498 \\
\hline$\$$ & 3.688 .585 & 260 & $\$$ & 80.009 .373 \\
\hline$\$$ & 4.426 .302 & 260 & $\$$ & 96.011 .247 \\
\hline$\$$ & 5.164 .019 & 260 & $\$$ & 112.013 .122 \\
\hline$\$$ & 5.901 .736 & 260 & $\$$ & 128.014 .996 \\
\hline
\end{tabular}




\section{Fuente: Elaboración propia}

Los resultados obtenidos se calcularon con base en la comparación de tres esquemas:

- Los recursos estuvieron el $100 \%$ en el portafolio conservador.

- Los recursos estuvieron el $100 \%$ en el portafolio moderado.

- Los recursos estuvieron distribuidos entre el esquema multifondos.

Tabla 9: Resultados de la mesada pensional en el régimen privado

\begin{tabular}{|c|c|c|c|c|c|}
\hline \multicolumn{6}{|c|}{ REGIMEN PRIVADO } \\
\hline \multicolumn{2}{|c|}{$\begin{array}{l}\text { MESADA PENSIONAL } \\
100 \% \text { CONSERVADOR }\end{array}$} & \multicolumn{2}{|c|}{$\begin{array}{l}\text { MESADA PENSIONAL } \\
\text { 100\% MODERADO }\end{array}$} & \multicolumn{2}{|c|}{$\begin{array}{c}\text { MESADA PENSIONAL DISTRIBUCIÓN } \\
\text { ENTRE FONDOS }\end{array}$} \\
\hline$\$$ & 737.717 & $\$$ & 974.212 & $\$$ & 1.264 .837 \\
\hline$\$$ & 1.175 .915 & $\$$ & 1.948 .671 & $\$$ & 2.529 .992 \\
\hline$\$$ & 1.763 .873 & $\$$ & 2.923 .006 & $\$$ & 3.794 .988 \\
\hline$\$$ & 2.531 .830 & $\$$ & 3.897 .341 & $\$$ & 5.059 .983 \\
\hline$\$$ & 2.939 .788 & $\$$ & 4.871 .676 & $\$$ & 6.324 .979 \\
\hline$\$$ & 3.527 .745 & $\$$ & 5.846 .012 & $\$$ & 7.589 .975 \\
\hline$\$$ & 4.115 .703 & $\$$ & 6.820 .347 & $\$$ & 8.854 .971 \\
\hline$\$$ & 4.703 .660 & $\$$ & 7.794 .682 & $\$$ & 10.119 .967 \\
\hline
\end{tabular}

Fuente: Elaboración propia.

Se presentan diferencias significativas entre la gestión del capital de las personas, si se comparan los crecimientos de capitales dentro de cada uno de los portafolios de pensiones, encontrando, que para las personas jóvenes es fundamental contar con el esquema propuesto en la ley 1328 de 2009, con el fin de mejorar su calidad de vida en la etapa de vejez. 
Tabla 10: Resultados de la mesada pensional en el régimen prima media (RPM)

\begin{tabular}{|lc|cc|rc|}
\hline \multicolumn{7}{|c|}{ RPM } \\
\hline $\begin{array}{c}\text { MESADA REGIMEN PUBLICO } \\
\text { 100\% CONSERVADOR }\end{array}$ & $\begin{array}{c}\text { MESADA } \\
\text { PENSIONAL 100\% } \\
\text { MODERADO }\end{array}$ & $\begin{array}{l}\text { MESADA PENSIONAL DISTRIBUCIÓN ENTRE } \\
\text { FONDOS }\end{array}$ \\
\hline$\$$ & 737.717 & $\$$ & 737.717 & $\$$ & 737.717 \\
\hline$\$$ & 1.096 .383 & $\$$ & 1.096 .383 & $\$$ & 1.096 .383 \\
\hline$\$$ & 1.634 .229 & $\$$ & 1.634 .229 & $\$$ & 1.634 .229 \\
\hline$\$$ & 2.165 .179 & $\$$ & 2.165 .179 & $\$$ & 2.165 .179 \\
\hline$\$$ & 2.689 .233 & $\$$ & 2.689 .233 & $\$$ & 2.689 .233 \\
\hline$\$$ & 3.206 .390 & $\$$ & 3.206 .390 & $\$$ & 3.206 .390 \\
\hline$\$$ & 3.716 .651 & $\$$ & 3.716 .651 & $\$$ & 3.716 .651 \\
\hline$\$$ & 4.220 .015 & $\$$ & 4.220 .015 & $\$$ & 4.220 .015 \\
\hline
\end{tabular}

Fuente: Elaboración propia.

Los resultados encontrados en la tabla anterior, muestra que, para el fondo público de pensiones, no existe diferencias dentro de los esquemas incorporados (fondos) en la gestión de multiportafolios, que existe dentro del sector privado y el sector público, presentando a largo plazo que no es conveniente estar invertidos dentro de este tipo de estructuras, dado a los bajos crecimientos de capital que puede generar.

Al evidenciar los resultados dentro del régimen de ahorro individual y régimen de prima media, se observa que dada la capitalización del capital a través de la tasa de interés y el tiempo que permanece la inversión dentro del fondo. 


\section{Tabla 11. Resultados Régimen privado y Régimen de Prima Media}

\begin{tabular}{|cc|cc|}
\hline \multicolumn{2}{|c|}{ RPM } & \multicolumn{2}{c|}{ RAIS } \\
\hline$\$$ & 737.717 & $\$$ & 1.264 .837 \\
\hline$\$$ & 1.096 .383 & $\$$ & 2.529 .992 \\
\hline$\$$ & 1.634 .229 & $\$$ & 3.794 .988 \\
\hline$\$$ & 2.165 .179 & $\$$ & 5.059 .983 \\
\hline$\$$ & 2.689 .233 & $\$$ & 6.324 .979 \\
\hline$\$$ & 3.206 .390 & $\$$ & 7.589 .975 \\
\hline$\$$ & 3.716 .651 & $\$$ & 8.854 .971 \\
\hline$\$$ & 4.220 .015 & \$ 10.119 .967 \\
\hline
\end{tabular}

Fuente: Elaboración propia.

Se evidencia que los resultados obtenidos para los hombres entre 20 - 30 años de edad, obtienen una mesada pensional mejor dentro del sistema de pensiones privados, esto, se puede ver justificado por la capitalización de los recursos que pudo obtener dentro del esquema multiportafolio, definiendo así que en termino de largo plazo le será más beneficioso empezar a cotizar en un fondo privado y pensionarse en el mismo, con el fin de beneficiar aquellas personas que actualmente no tienen las condiciones suficientes para acceder a un pensión. . Adicionalmente la proporción entre el salario actual y el salario futuro muestra que, a través de esta estrategia, se reducen las brechas de ingreso para las personas en su vejez, lo cual mantendrá la calidad de vida a lo largo del tiempo.

\section{MUJERES: RANGO DE EDAD 20 -30 AÑOS}

\section{Las variables que se tomaran en cuenta:}

- Ingreso: Los datos fueron tomados desde un salario hasta 8 salarios mínimos. Multiplicando el valor inicial por la cantidad de salarios. 
- Semanas cotizadas 1994: Se asumen 0 semanas, porque son personas que nacieron entre los años 80 y 90, por lo cual no ejercen como afiliados al sistema en este año.

- Semanas cotizadas: Se consideraron 260 semanas con una confiabilidad del 50\% de aportes al sistema, dado que pueden pasar que la persona quede cesante por algunos meses y no pueda aportar al sistema.

- Capital en cuenta individual: Se lleva a valor futuro del valor del aporte mensual durante los 10 años, teniendo en cuenta la capitalización mensual de los aportes.

Tabla 12: Variables a considerar en el cálculo de la mesada pensional Mujer 20 - 30 años.

\begin{tabular}{|lr|c|rr|}
\hline \multicolumn{5}{|c|}{ EDAD 20 A 30 AÑOS } \\
\hline \multirow{2}{*}{$\begin{array}{c}\text { INGRESO } \\
\text { SEMANAS COTIZADAS A } \\
\text { REGIMEN DE AHORRO } \\
\text { INDIVIDUAL }\end{array}$} & $\begin{array}{l}\text { CAPITAL EN CUENTA } \\
\text { INDIVIDUAL }\end{array}$ \\
\hline$\$$ & 737.717 & 260 & $\$$ & 16.001 .875 \\
\hline$\$$ & 1.475 .434 & 260 & $\$$ & 32.003 .749 \\
\hline$\$$ & 2.213 .151 & 260 & $\$$ & 48.005 .624 \\
\hline$\$$ & 2.950 .868 & 260 & $\$$ & 64.007 .498 \\
\hline$\$$ & 3.688 .585 & 260 & $\$$ & 80.009 .373 \\
\hline$\$$ & 4.426 .302 & 260 & $\$$ & 96.011 .247 \\
\hline$\$$ & 5.164 .019 & 260 & $\$$ & 112.013 .122 \\
\hline$\$$ & 5.901 .736 & 260 & $\$$ & 128.014 .996 \\
\hline
\end{tabular}

Fuente: Elaboración propia

Los resultados obtenidos se calcularon con base en la comparación de tres esquemas:

- Los recursos estuvieron el $100 \%$ en el portafolio conservador.

- Los recursos estuvieron el $100 \%$ en el portafolio moderado.

- Los recursos estuvieron distribuidos entre el esquema multifondos. 
Tabla 13: Resultados de la mesada pensional en el régimen privado

\begin{tabular}{|cc|c|rc|}
\hline \multicolumn{2}{|c|}{ CONSERVADOR 100\% } & \multirow{2}{*}{ MODERADO 100\% } & \multicolumn{2}{c|}{ ESQUEMA MULTIFONDOS } \\
\hline$\$$ & 737.717 & $\$ 737.717$ & $\$$ & 896.710 \\
\hline$\$$ & 977.637 & $\$ 1.495 .894$ & $\$$ & 1.793 .529 \\
\hline$\$$ & 1.466 .455 & $\$ 2.243 .841$ & $\$$ & 2.690 .293 \\
\hline$\$$ & 1.955 .273 & $\$ 2.991 .788$ & $\$$ & 3.587 .058 \\
\hline$\$$ & 2.440 .920 & $\$ 3.739 .734$ & $\$$ & 4.483 .822 \\
\hline$\$$ & 2.932 .910 & $\$ 4.487 .681$ & $\$$ & 5.380 .587 \\
\hline$\$$ & 3.421 .728 & $\$ 5.235 .628$ & $\$$ & 6.064 .590 \\
\hline$\$$ & 3.910 .547 & $\$ 5.983 .575$ & $\$$ & 6.277 .351 \\
\hline
\end{tabular}

Fuente: Elaboración propia

Tabla 14: Resultados de la mesada pensional en el régimen prima media (RPM)

\begin{tabular}{|cc|c|rc|}
\hline \multicolumn{2}{|c|}{ CONSERVADOR 100\% } & MODERADO 100\% & \multicolumn{2}{c|}{ ESQUEMA MULTIFONDOS } \\
\hline$\$$ & 737.717 & $\$ 737.717$ & $\$$ & 737.717 \\
\hline$\$$ & 1.096 .383 & $\$ 1.096 .383$ & $\$$ & 1.096 .383 \\
\hline$\$$ & 1.634 .229 & $\$ 1.634 .229$ & $\$$ & 1.634 .229 \\
\hline$\$$ & 1.689 .233 & $\$ 1.689 .233$ & $\$$ & 1.689 .233 \\
\hline$\$$ & 2.161 .179 & $\$ 2.161 .179$ & $\$$ & 2.161 .179 \\
\hline$\$$ & 3.206 .390 & $\$ 3.206 .390$ & $\$$ & 3.206 .390 \\
\hline$\$$ & 3.716 .651 & $\$ 3.716 .651$ & $\$$ & 3.716 .651 \\
\hline$\$$ & 4.220 .015 & $\$ 4.220 .015$ & $\$$ & 4.220 .015 \\
\hline
\end{tabular}

Fuente: Elaboración propia

Para las mujeres existen mayores ventajas dentro de Colpensiones, ya que, bajo las mismas cotizaciones de los hombres, no presentan diferencias significativas, como se ven dentro del régimen privado dado la baja capitalización en términos de tiempo, la edad de pensión.

Tabla 15. Resultados entre hombres y mujeres Régimen Privado 


\begin{tabular}{|c|c|c|}
\hline \multicolumn{2}{|r|}{ HOMBRE } & MUJER \\
\hline$\$$ & 1.264 .837 & $\$ \quad 896.710$ \\
\hline$\$$ & 2.529 .992 & $\$ 1.793 .529$ \\
\hline$\$$ & 3.794 .988 & $\$ 2.690 .293$ \\
\hline$\$$ & 5.059 .983 & $\$ 3.587 .058$ \\
\hline$\$$ & 6.324 .979 & $\$ 4.483 .822$ \\
\hline$\$$ & 7.589 .975 & $\$ 5.380 .587$ \\
\hline & 8.854 .971 & $\$ 6.064 .590$ \\
\hline & 10.119 .967 & $\$ 6.277 .351$ \\
\hline
\end{tabular}

\section{Fuente: Elaboración propia}

A pesar de que se encuentran diferencias entre ambos regímenes, se evidencia que si ambos usuarios (hombre y mujer) cotizaran en el Régimen de Prima Media, estarían en las mismas condiciones, mientras que las mujeres presentan una desventaja en comparación a los hombres, en el régimen ahorro individual, debido a que su salario es en promedio $40 \%$ menor que el de los hombres.

Por ello se observa que existe una diferencia en términos de condiciones de generó en el régimen privado de pensiones. Mostrando que el sistema público es más equitativo salarialmente.

\section{RESULTADOS}

1. Las diferencias entre brechas de ingresos no existen, cuando se ahorra desde que se empieza a trabajar.

2. El modelo de diversificación de multiportafolios fue diseñado para que se pueda tener una capitalización mayor de los ingresos de las personas, con el fin de mantener el equilibrio de los dos regímenes actuales en Colombia. 
3. Se puede evidenciar la necesidad de políticas de ahorro, que poyen al sostenimiento del sistema pensional actualmente establecido, además aportar desde el punto de vista económico y social, mejora calidad de vida de las personas en su etapa de vejez.

4. Políticas de ahorro para jóvenes que están en la Universidad obligatorias para pensión., a través de los diversos instrumentos financieros (CDT, Cuenta de Ahorro, fiduciaria, fondo de pensión voluntaria, entre otros).

5. Las brechas de ingreso entre hombre y mujeres se ven muy enmarcadas con respecto al tiempo de cotización, por ello se puede establecer ayudas económicas de ahorro a largo plazo para igualar estas condiciones. Además, se asume que la carga laboral de las mujeres es mayor a la de los hombres y el ingreso al mercado laboral es más limitados para ellas. Lo cual puede solucionar a través de apoyos económicos en la etapa productiva de la mujer, que permita establecer un equilibrio en las mesadas pensionales entre hombres y mujeres,

6. Encontrar soluciones de que permitan evitar la evasión de seguridad social, que permita mejorar las condiciones de los pensionados, mostrando instrumentos financieros, que apoyen desde aportes bajos, a la construcción de una mesada pensional digna. 


\section{CONCLUSIONES}

Se puede evidenciar en el desarrollo del trabajo, que la literatura acerca de las aplicaciones o análisis en el mercado pensional han sido muy escazas en términos del comportamiento de estos fondos, permitiendo encontrar nuevas herramientas para calcular y entender cómo funciona este tipo de fondos de largo plazo dentro del mercado financiero.

Las investigaciones recientes que se han realizado son evidencia particularmente fuerte para deducir que no todos los mercados mantienen un comportamiento basado en la hipótesis de mercados eficientes, sosteniendo la importancia de ampliar la información acerca del análisis de este tipo de estructuras.

Lo anterior permite reducir la asimetría de información y complementar los modelos tradicionales, generando una administración del riesgo, lo cual empieza a tomar gran relevancia desde el punto de vista financiero y pensional, conllevando a darle la importancia debida a este tema, ya que, tanto para personas como empresas, es vital para una administración optima y una toma de decisiones más acertada.

Por ello, es de vital importancia ver que no solo la teoría de portafolios eficientes son mecanismo de medición desde el punto de vista financiero, sino que existen diferentes métodos (persistencia y antipersistencia) que apoyan y complementan el fortalecimiento del cálculo del tema de riesgo y rendimiento dentro de un portafolio y que, además, puede llegar hacer relevante y significativo en la toma de decisiones del individuo.

Complementando lo observado en este estudio se encuentra que dentro del análisis de la ley 1328 de 2009 existen instrumentos que permiten tomar mejores decisiones a los 
individuos, incrementando las probabilidades de ahorro y sostenibilidad del sistema. Esto a partir de la reducción de las brechas de ingreso y los enfoques en los que se debe direccionar el gobierno nacional, en pro de transformar hacia la sostenibilidad del fondo público, enfocado en el auxilio para aquellas personas que no tengan las posibilidades para acceder a una pensión, permitiendo la administración de los fondos privados y en mayor proporción de los recursos de los colombianos.

Además, evidenciamos la crisis que actualmente sufre Colpensiones actualmente con los desfalcos y la falta de recursos que tiene para ser sostenible en el tiempo, muestra un panorama de ajustes dentro de este sistema. Por ello empieza a tomar gran relevancia los ajustes en términos de ahorro, políticas que reformen estructuralmente el sistema pensional (aumento de la edad de pensión, reajustes en los porcentajes de seguridad social) y que promueva la igualdad entre hombres y mujeres.

Por ello es de vital importancia que se sigan desarrollando estos trabajos, que permitan entenderle a las personas como es la realidad económica, pensional y de calidad de vida, con el fin de que las condiciones socioeconómicas dentro del país mejoren en pro de las personas que actualmente se encuentran en el sistema. Permitiendo reducir la asimetría de información o desconocimiento de la información que proporciona este mercado y que le permita tomar mejores decisiones que impactaran de forma positiva su etapa de jubilación.

Finalmente se pudo evidenciar para dar respuesta a la pregunta de investigación, que existe otros modelos diferentes, a la teoría de portafolios eficientes que permiten complementar el análisis y administración de este tipo de fondos. Además, que se puede determinar que la implementación de la ley 1328 de 2009, mejora las condiciones de vida de las personas, con el fin de permitir la obtención de una mejor mesada pensional. 


\section{BIBLIOGRAFÍA}

Alonso F, R. F. (s.f.). La remuneracion de la volatilidad en el mercado espanol de rebta variable. Banco de Espana, 57.

Bachelier, L. 1900. "Théorie de la Spéculation ", Tesis doctoral en " Sciences Mathématiques", publicada en Annales de l’Ecole Normale Supérieure, tomo 17, 2186.

Barcelona, F. E. (Noviembre de 2001). Modelización No Browniana de series temporales financieras. Obtenido de http://www.tdx.cat/bitstream/handle/10803/2131/TESISESPINOSA.pdf.txt?sequenc $\mathrm{e}=2$

Bartoli, F. (2005). A multiscale study of silty soil structure. Wiley.

Battle, A., \& Grebol, S. (2008). Fractales en los mercados Financieros. Barcelona.

Benjamín, D. D., Suárez, S., Julieth, K., \& Mascareñas, J. M. (20014). Evaluación de la memoria de Largo Plazo del mercado Bursatil Colombiano Mediante el coeficiente de Hurst. Revista Internacional Administración y Finanzas, 1-11.

Botero, J. H. (2017). Fasecolda advierte "catástrofe social" si se mantiene el régimen pensional. Dinero.

Box, G.E.P., C.M. Jenkins. 1970. Time series analysis forecasting and control. Holden Day, San Francisco.

Brianto, M. (2010). Mercado de capitales y crecimiento economico> caso venezuela . Bnaco General de venezuela, 40.

Carr, J. (1997). Statistical self-affinity, . Engineering Geology, 269 - 282.

Dominguez, D., Ardila, E., \& Moreno, J. F. (2010). Metodología e interpretación del coeficiente de Hurst. ODEON, 267-290. 
Engle, R. (1982). Autorregressive Conditional Heteroscedasticity with Estimates of the Variance of United Kingdom Inflation. Econometrica, 987 - 1008.

Espinosa, C. (2007). Memoria de largo plazo y efecto reset en retornos accionarios lationamericanos. Estudios de Administración, 47-70.

Fama, E. (1969). The Adjustmen Of Stock Prices To New information. International Economic Revieqw, 1-21.

Friedman, M. (1957). Introduction to "A Theory of the Consumption Function". National Bureau of Economic Research, 1 -6.

Greene, M. y B. FIELITZ (1977), “Long term dependence in common stock returns”, Journal of Financial Economics.

Hurst, H.E., 1951. Long-term storage capacity of reservoirs. Transactions of the American Society of Civil Engineers, Volume 116, Pages 770_-799.

Kiyosaki, R. (2000). Padre rico padre pobre. Aguilar.

Kyaw, N., C. LOS y S. ZONG (2004), "Persistence characteristics of Latin American financial markets", Journal of Multinational Financial Management 15.

Leon, C., \& Vivas, F. (2010). Dependencia de largo plazo y la regla de la raiz del tiempo para escalar la volatilidad en el mercado colombiano. Borradores de Economía, 149.

Lipka, J.M. y C. LOS (2003), “Long-Term Dependence Characteristics of European Stock Indices", Economics Working Paper Archive, EconWPA, Finance No 0409044.

Los, C. y B. YU (2005), "Persistence Characteristics of the Chinese Stock Markets", Economics Working Paper Archive, EconWPA, Finance No 0508008.

Mandelbrot, B. (1966). Forecast of Future Prices, Unbiased Markets and Martingale Models. Mc Graw-Hill.

Mandelbrot, B. (1982). The Fractal Geometry of Nature. San Francisco: Freeman. Modgliani, F., \& Brumberg, R. (1954). "Utility analysis and tje consumption function: an intepretation of cross-section data". PostKeynesian Economics, 338-436. 
Nawrocki, D. (1995). R/S Analysis and Long Term Dependence in Stock Market Indices. Villanova: Managerial Financie.

Oliveira, M. (2017). De 21 millones de trabajadores, 7 millones cotizan y solo 2 millones logran pensionarse. Colpensiones.

Peters, E. (1994). Fractal market analysis applying chaos theory to invesment and economics. New York: Wiley.

Peters, E. (1992), “R/S Analysis Using Logarithmic Returns: A Technical Note”, Financial Analysts Journal, 48 - 6, November/December, pp. 81-82.

Rodriguez, J. L. (2011). Validez del supuesto de Neutralidad del horizonte en el CAPM y la metodología del Rango Reescalado: Aplicaciín a Colombia. Borradores de Economía.

Rodriguez Solorzano, L. (2013). Calculo Fractal de la variabilidad del CD4 para la determinación del costo de la prima mensual de un seguro de VIH. Cuadernos Latinoamericanos de administración, 106-113.

Rufino, I., \& Jovanovich, C. (2014). FRACTALES, ECONOMÍA Y EMPRESAS. TRIM, 19.

Silvapulle, Param, S., \& Shibley. (2001). Long-term memory in stock market returns: international evidence. International Journal of Finance \& Economics, 59-67.

SuperFinanciera. (Septiembre de 2017). Superintendencia financiera de Colombia. Obtenido de https://www.superfinanciera.gov.co/jsp/loader.jsf?1Servicio=Publicaciones\&1Tipo= publicaciones\&lFuncion=loadContenidoPublicacion\&id=9125

Torres, S. R. (3 de Octubre de 2012). Memoria de largo plazo en el indice S\&P 500: Un enfoque fractal aplicando el coeficiente de Hurst con el metodo R/S. Mexico, Mexico.

Treviño, B., \& Garcias, R. (21 de 03 de 2013). El Economista. Obtenido de Un portafolio para cada perfil: http://eleconomista.com.mx/finanzaspersonales/2013/03/21/portafolio-cada-perfil

Velásquez, H., \& Restrepo, J. H. (2012). ANÁLISIS DEL ÍNDICE GENERAL DE LA BOLSA DE VALORES DE COLOMBIA Y SUS RENDIMIENTOS DESDE LA TEORÍA DEL CAOS, 2001 - 2011. SEMESTRE ECONÓMICO, 79 -98. 
Villaseñor Baez, L. G., \& Alcaraz Vera, J. V. (2010). Antecedentes fractales para mercados financieros. INCEPTUM, 263-292.

Vucovich, Audelo, C., Estela, B., \& Carlos. (2015). Tendencia de la Dinámica No-Lineal en una Precontingencia Ambiental causada por Partículas en Suspensión. EBSCO, 21-28. 


\section{ANEXOS}

PORTAFOLIO MODERADO

Anexo 1. Valor fondo moderado año 2016

\begin{tabular}{|c|c|c|c|c|c|c|c|c|c|}
\hline FONDO MODERADO & PORVENIR & \multicolumn{2}{|c|}{ PROTECCION } & \multicolumn{2}{|c|}{ COLFONDOS } & \multicolumn{2}{|c|}{ OLD MUTUAL } & \multicolumn{2}{|r|}{ TOTAL } \\
\hline ENERO & $\$ 64.473 .586$ & $\$$ & 50.673 .661 & $\$$ & 18.971 .036 & $\$$ & 7.413 .234 & $\$$ & 141.531 .517 \\
\hline FEBRERO & $\$ 65.071 .944$ & $\$$ & 51.029 .188 & $\$$ & 19.016 .898 & $\$$ & 7.517 .763 & $\$$ & 142.635 .793 \\
\hline MARZO & $\$ 66.977 .802$ & $\$$ & 52.367 .568 & $\$$ & 19.538 .844 & $\$$ & 7.779 .743 & $\$$ & 146.663 .957 \\
\hline ABRIL & $\$ 66.983 .665$ & $\$$ & 52.465 .663 & $\$$ & 19.521 .638 & $\$$ & 1.676 & $\$$ & 2.642 \\
\hline MAYO & .059 & $\$$ & 53.365 .166 & $\$$ & & $\$$ & 7.964 .640 & $\$$ & .415 \\
\hline JUNIO & $\$ 68$ & $\$$ & 53.211 .391 & $\$$ & 4.087 & $\$$ & 3.141 & $\$$ & 4.294 \\
\hline JULIO & $\$ 70$ & $\$$ & .840 & 4 & 20. & $\$$ & 86 & $\$$ & 39.465 \\
\hline AGOSTO & $\$ 70$ & $\$$ & 55.1 & $\$$ & 20. & $\$$ & 67 & $\$$ & 4.607 \\
\hline SEPTIEMBRE & $\$ 70$. & 4 & 55.2 & $\$$ & 8.867 & $\$$ & .789 & $\$$ & 8.919 \\
\hline OCTUBRE & $\$ 72.344 .668$ & $\$$ & 56.177 .997 & $\$$ & 20.953 .886 & $\$$ & 8.501 .163 & $\$$ & 157.977 .714 \\
\hline NOVIEMBRE & $\$ 71.854 .842$ & $\$$ & 55.792 .614 & $\$$ & 20.798 .682 & $\$$ & 8.517 .467 & $\$$ & 156.963 .605 \\
\hline DICIEMBRE & $\$ 72.996 .498$ & $\psi$ & 56.731 .121 & $\$$ & 21.142 .840 & $\$$ & 8.644 .490 & $\$$ & 159.514 .948 \\
\hline
\end{tabular}

Fuente: Elaboración propia con base a datos de valor de fondo de la Superintendencia Financiera

Anexo 2. Valor fondo moderado año 2015

\begin{tabular}{|c|c|c|c|c|c|c|c|c|c|}
\hline FONDO MODERADO & PORVENIR & \multicolumn{2}{|c|}{ PROTECCION } & \multicolumn{2}{|c|}{ COLFONDOS } & \multicolumn{2}{|c|}{ OLD MUTUAL } & \multicolumn{2}{|r|}{ TOTAL } \\
\hline ENERO & $\$ 59.662 .025$ & $\$$ & 47.433 .256 & $\$$ & 17.968 .964 & $\$$ & 6.519 .731 & $\$$ & 131.583 .976 \\
\hline FEBRERO & $\$ 60.965 .125$ & $\$$ & 48.231 .707 & $\$$ & 18.292 .805 & $\$$ & 6.684 .110 & $\$$ & 134.173 .748 \\
\hline MARZO & $\$ 61.185 .996$ & $\$$ & 48.277 .923 & $\$$ & 18.197 .250 & $\$$ & 6.736 .357 & $\$$ & 134.397 .526 \\
\hline ABRIL & $\$ 62.102 .225$ & $\$$ & 48.815 .329 & $\$$ & 18.443 .294 & $\$$ & 6.840 .082 & $\$$ & 136.200 .930 \\
\hline MAYO & $\$ 62.033 .000$ & $\$$ & 48.855 .851 & $\$$ & 18.453 .990 & $\$$ & 6.840 .369 & $\$$ & 136.183 .210 \\
\hline JUNIO & $\$ 62.006 .700$ & $\$$ & 48.936 .342 & $\$$ & 18.450 .066 & $\$$ & 6.926 .203 & $\$$ & 136.319.312 \\
\hline JULIO & $\$ 64.000 .379$ & $\$$ & 50.569 .436 & $\$$ & 19.081 .031 & $\$$ & 7.218 .383 & $\$$ & 140.869 .230 \\
\hline AGOSTO & $\$ 62.824 .432$ & $\$$ & 49.685.316 & $\$$ & 18.700 .397 & $\$$ & 7.173 .541 & $\$$ & 138.383 .686 \\
\hline SEPTIEMBRE & $\$ 61.879 .329$ & $\$$ & 48.985 .718 & $\$$ & 18.465 .826 & $\$$ & 7.117 .880 & $\$$ & 136.448 .753 \\
\hline OCTUBRE & $\$ 63.363 .219$ & $\$$ & 50.447 .401 & $\$$ & 18.874 .005 & $\$$ & 7.351.251 & $\$$ & 140.035 .876 \\
\hline NOVIEMBRE & $\$ 63.590 .493$ & $\$$ & 50.592 .744 & $\$$ & 18.896 .062 & $\$$ & 7.354 .840 & $\$$ & 140.434 .139 \\
\hline DICIEMBRE & $\$ 64.448 .818$ & $\$$ & 50.948 .988 & $\$$ & 18.981 .301 & $\$$ & 7.415 .029 & $\$$ & 141.794 .136 \\
\hline
\end{tabular}

Fuente: Elaboración propia con base a datos de valor de fondo de la Superintendencia Financiera 
Anexo 3. Valor fondo moderado año 2014

\begin{tabular}{|c|c|c|c|c|c|c|c|c|c|}
\hline FONDO MODERADO & PORVENIR & \multicolumn{2}{|c|}{ PROTECCION } & \multicolumn{2}{|c|}{ COLFONDOS } & \multicolumn{2}{|c|}{ OLD MUTUAL } & \multicolumn{2}{|r|}{ TOTAL } \\
\hline ENERO & $\$ 59.662 .025$ & $\$$ & 47.433 .256 & $\$$ & 17.968 .964 & $\$$ & 6.519 .731 & $\$$ & 131.583 .976 \\
\hline FEBRERO & $\$ 60.965 .125$ & $\$$ & 48.231 .707 & $\$$ & 18.292 .805 & $\$$ & 6.684 .110 & $\$$ & 134.173 .748 \\
\hline MARZO & $\$ 61.185 .996$ & $\$$ & 48.277 .923 & $\$$ & 18.197 .250 & $\$$ & 6.736 .357 & $\$$ & 134.397 .526 \\
\hline ABRIL & $\$ 62.102 .225$ & $\$$ & 48.815 .329 & $\$$ & 18.443 .294 & $\$$ & 6.840 .082 & $\$$ & 136.200 .930 \\
\hline MAYO & $\$ 62.033 .000$ & $\$$ & 48.855 .851 & $\$$ & 18.453 .990 & $\$$ & 6.840 .369 & $\$$ & 136.183 .210 \\
\hline JUNIO & $\$ 62.006 .700$ & $\$$ & 48.936 .342 & $\$$ & 18.450 .066 & $\$$ & 6.926 .203 & $\$$ & 136.319 .312 \\
\hline JULIO & $\$ 64.000 .379$ & $\$$ & 50.569 .436 & $\$$ & 19.081 .031 & $\$$ & 7.218 .383 & $\$$ & 140.869 .230 \\
\hline AGOSTO & $\$ 62.824 .432$ & $\$$ & 49.685 .316 & $\$$ & 18.700 .397 & $\$$ & 7.173 .541 & $\$$ & 138.383 .686 \\
\hline SEPTIEMBRE & $\$ 61.879 .329$ & $\$$ & 48.985 .718 & $\$$ & 18.465 .826 & $\$$ & 7.117 .880 & $\$$ & 136.448 .753 \\
\hline OCTUBRE & $\$ 63.363 .219$ & $\$$ & 50.447 .401 & $\$$ & 18.874 .005 & $\$$ & 7.351.251 & $\$$ & 140.035 .876 \\
\hline NOVIEMBRE & $\$ 63.590 .493$ & $\$$ & 50.592 .744 & $\$$ & 18.896 .062 & $\$$ & 7.354 .840 & $\$$ & 140.434 .139 \\
\hline DICIEMBRE & $\$ 64.448 .818$ & $\$$ & 50.948 .988 & $\$$ & 18.981 .301 & $\$$ & 7.415 .029 & $\$$ & 141.794 .136 \\
\hline
\end{tabular}

Fuente: Elaboración propia con base a datos de valor de fondo de la Superintendencia Financiera

Anexo 4. Valor fondo moderado año 2013

\begin{tabular}{|c|c|c|c|c|c|c|c|c|c|}
\hline FONDO MODERADO & PORVENIR & \multicolumn{2}{|c|}{ PROTECCION } & \multicolumn{2}{|c|}{ COLFONDOS } & \multicolumn{2}{|c|}{ OLD MUTUAL } & \multicolumn{2}{|r|}{ TOTAL } \\
\hline ENERO & $\$ 49.629 .959$ & $\$$ & 39.762 .464 & $\$$ & 15.022 .592 & $\$$ & 5.369 .511 & $\$$ & 109.784 .526 \\
\hline FEBRERO & $\$ 50.995 .172$ & $\$$ & 40.855 .922 & $\$$ & 15.431 .531 & $\$$ & 5.512 .537 & $\$$ & 112.795 .163 \\
\hline MARZO & $\$ 53.531 .010$ & $\$$ & 42.820 .127 & $\$$ & 16.154 .011 & $\$$ & 5.810 .698 & $\$$ & 118.315 .846 \\
\hline ABRIL & $\$ 54.369 .319$ & $\$$ & 43.434 .461 & $\$$ & 16.351 .568 & $\$$ & 5.914 .727 & $\$$ & 120.070 .075 \\
\hline MAYO & $\$ 54.958 .443$ & $\$$ & 43.760 .919 & $\$$ & 16.485 .072 & $\$$ & 5.913 .396 & $\$$ & 121.117 .829 \\
\hline JUNIO & $\$ 55.648 .377$ & $\$$ & 44.315 .819 & $\$$ & 16.712 .830 & $\$$ & 6.076 .764 & $\$$ & 122.753 .790 \\
\hline JULIO & $\$ 56.195 .490$ & $\$$ & 44.524 .639 & $\$$ & 16.813 .490 & $\$$ & 6.129 .183 & $\$$ & 123.662 .802 \\
\hline AGOSTO & $\$ 58.077 .523$ & $\$$ & 46.002 .269 & $\$$ & 17.329 .496 & $\$$ & 6.310 .480 & $\$$ & 127.719 .768 \\
\hline SEPTIEMBRE & $\$ 57.437 .801$ & $\$$ & 45.377 .866 & $\$$ & 17.125 .018 & $\$$ & 6.236 .466 & $\$$ & 126.177 .152 \\
\hline OCTUBRE & $\$ 58.202 .971$ & $\$$ & 46.022 .875 & $\$$ & 17.440 .602 & $\$$ & 6.359 .317 & $\$$ & 128.025 .765 \\
\hline NOVIEMBRE & $\$ 58.725 .635$ & $\$$ & 46.406 .434 & $\$$ & 17.616 .222 & $\$$ & 6.417 .285 & $\$$ & 129.165 .576 \\
\hline DICIEMBRE & $\$ 59.740 .181$ & $\$$ & 47.412 .935 & $\$$ & 17.915 .632 & $\$$ & 6.532 .850 & $\$$ & 131.601 .598 \\
\hline
\end{tabular}

Fuente: Elaboración propia con base a datos de valor de fondo de la Superintendencia Financiera 
Anexo 5. Valor fondo moderado año 2012

\begin{tabular}{|c|c|c|c|c|c|c|c|c|c|}
\hline FONDO MODERADO & PORVENIR & \multicolumn{2}{|c|}{ PROTECCION } & \multicolumn{2}{|c|}{ COLFONDOS } & \multicolumn{2}{|c|}{ SKANDIA } & \multicolumn{2}{|r|}{ TOTAL } \\
\hline ENERO & $\$ 32.810 .558$ & $\$$ & 40.897 .169 & $\$$ & 15.276 .972 & $\$$ & 5.329 .989 & $\$$ & 94.314 .687 \\
\hline FEBRERO & $\$ 33.050 .428$ & $\$$ & 41.080 .740 & $\$$ & 15.343 .961 & $\$$ & 5.358 .329 & $\$$ & 94.833 .458 \\
\hline MARZO & $\$ 33.008 .591$ & $\$$ & 41.005 .153 & $\$$ & 15.317 .258 & $\$$ & 5.370 .699 & $\$$ & 94.701 .702 \\
\hline ABRIL & $\$ 32.911 .501$ & $\$$ & 40.805 .311 & $\$$ & 15.234 .543 & $\$$ & 5.351 .635 & $\$$ & 94.302 .991 \\
\hline MAYO & $\$ 32.611 .936$ & $\$$ & 40.122 .095 & $\$$ & 15.095 .998 & $\$$ & 5.274 .064 & $\$$ & 93.104 .093 \\
\hline JUNIO & $\$ 31.572 .339$ & $\$$ & 38.792 .573 & $\$$ & 14.625 .299 & $\$$ & 5.091 .429 & $\$$ & 90.081 .639 \\
\hline JULIO & $\$ 32.119 .742$ & $\$$ & 39.521 .667 & $\$$ & 14.840 .865 & $\$$ & 5.208 .390 & $\$$ & 91.690 .664 \\
\hline AGOSTO & $\$ 32.523 .652$ & $\$$ & 39.960 .999 & $\$$ & 14.990 .027 & $\$$ & 5.257 .281 & $\$$ & 92.731 .960 \\
\hline SEPTIEMBRE & $\$ 33.176 .055$ & $\$$ & 40.839 .833 & $\$$ & 15.276 .112 & $\$$ & 5.388 .265 & $\$$ & 94.680 .266 \\
\hline OCTUBRE & $\$ 33.755 .776$ & $\$$ & 41.452 .535 & $\$$ & 15.475 .657 & $\$$ & 5.499 .360 & $\$$ & 96.183 .329 \\
\hline NOVIEMBRE & $\$ 33.224 .490$ & $\$$ & 40.664 .101 & $\$$ & 15.196 .744 & $\$$ & 5.425 .540 & $\$$ & 94.510 .876 \\
\hline DICIEMBRE & $\$ 33.312 .721$ & $\$$ & 40.746 .740 & $\$$ & 15.309 .601 & $\$$ & 5.609 .062 & $\$$ & 94.978 .124 \\
\hline
\end{tabular}

Fuente: Elaboración propia con base a datos de valor de fondo de la Superintendencia Financiera

Anexo 6. Valor fondo moderado año 2011

\begin{tabular}{|c|l|l|l|l|ll|lr|}
\hline FONDO MODERADO & PORVENIR & PROTECCION & \multicolumn{2}{l|}{ COLFONDOS } & \multicolumn{2}{l|}{ SKANDIA } & \multicolumn{1}{l|}{ TOTAL } \\
\hline ENERO & 26.847 .452 & $\$ 24.904 .538$ & $\$ 13.890 .372$ & $\$$ & 4.814 .742 & $\$$ & 70.457 .104 \\
\hline FEBRERO & 27.066 .631 & $\$ 25.010 .676$ & $\$$ & 13.947 .563 & $\$$ & 4.830 .225 & $\$$ & 70.855 .095 \\
\hline MARZO & 25.901 .484 & $\$ 21.717 .201$ & $\$$ & 12.265 .548 & $\$$ & 4.231 .141 & $\$$ & 64.115 .374 \\
\hline ABRIL & 26.144 .763 & $\$ 21.801 .964$ & $\$$ & 12.347 .602 & $\$$ & 4.261 .560 & $\$$ & 64.555 .889 \\
\hline MAYO & 26.690 .503 & $\$ 22.250 .753$ & $\$$ & 12.613 .716 & $\$$ & 4.330 .450 & $\$$ & 65.885 .421 \\
\hline JUNIO & 26.472 .538 & $\$ 22.023 .717$ & $\$$ & 12.485 .026 & $\$$ & 4.308 .582 & $\$$ & 65.289 .864 \\
\hline JULIO & 26.397 .253 & $\$ 21.990 .667$ & $\$$ & 12.448 .103 & $\$$ & 4.269 .921 & $\$$ & 65.105 .944 \\
\hline AGOSTO & 26.474 .366 & $\$ 22.163 .485$ & $\$$ & 12.520 .709 & $\$$ & 4.304 .551 & $\$$ & 65.463 .111 \\
\hline SEPTIEMBRE & 25.969 .938 & $\$ 21.539 .216$ & $\$$ & 12.244 .814 & $\$$ & 4.247 .865 & $\$$ & 64.001 .833 \\
\hline OCTUBRE & 26.710 .241 & $\$ 22.151 .333$ & $\$$ & 12.506 .977 & $\$$ & 4.345 .449 & $\$$ & 65.714 .000 \\
\hline NOVIEMBRE & 26.406 .049 & $\$ 21.868 .918$ & $\$$ & 12.330 .133 & $\$$ & 4.293 .306 & $\$$ & 64.898 .406 \\
\hline DICIEMBRE & 26.737 .499 & $\$ 22.102 .268$ & $\$$ & 12.427 .026 & $\$$ & 4.357 .775 & $\$$ & 65.624 .568 \\
\hline
\end{tabular}

Fuente: Elaboración propia con base a datos de valor de fondo de la Superintendencia Financiera 
Anexo 7. Valor fondo moderado año 2010

\begin{tabular}{|c|c|c|c|c|c|}
\hline FONDO CONSERVADOR & PORVENIR & PROTECCION & HORIZONTE & SKANDIA & TOTAL \\
\hline ENERO & $\$ 21.456 .541$ & $\$ 20.330 .049$ & $\$ 12.947 .498$ & $\$ 3.857 .835$ & $\$ 58.591 .923$ \\
\hline FEBRERO & $\$ 21.712 .538$ & $\$ 20.578 .711$ & $\$ 13.089 .139$ & $\$ 3.904 .408$ & $\$ 59.284 .795$ \\
\hline MARZO & $\$ 22.466 .723$ & $\$ 21.165 .368$ & $\$ 13.433 .663$ & $\$ 4.028 .278$ & $\$ 61.094 .033$ \\
\hline ABRIL & $\$ 23.016 .643$ & $\$ 21.643 .694$ & $\$ 13.739 .722$ & $\$ 4.149 .885$ & $\$ 62.549 .943$ \\
\hline MAYO & $\$ 23.103 .236$ & $\$ 21.610 .879$ & $\$ 13.770 .091$ & $\$ 4.136 .314$ & $\$ 62.620 .520$ \\
\hline JUNIO & $\$ 23.364 .678$ & $\$ 21.975 .407$ & $\$ 13.968 .022$ & $\$ 4.229 .668$ & $\$ 63.537 .775$ \\
\hline JULIO & $\$ 24.617 .532$ & $\$ 23.103 .382$ & $\$ 14.661 .931$ & $\$ 4.430 .079$ & $\$ 66.812 .924$ \\
\hline AGOSTO & $\$ 25.406 .079$ & $\$ 23.815 .728$ & $\$ 15.104 .597$ & $\$ 4.583 .637$ & $\$ 68.910 .041$ \\
\hline SEPTIEMBRE & $\$ 26.249 .773$ & $\$ 24.557 .123$ & $\$ 15.372 .449$ & $\$ 4.688 .725$ & $\$ 70.868 .071$ \\
\hline OCTUBRE & $\$ 27.232 .382$ & $\$ 25.463 .563$ & $\$ 15.920 .504$ & $\$ 4.900 .343$ & $\$ 73.516 .792$ \\
\hline NOVIEMBRE & $\$ 26.569 .958$ & $\$ 24.749 .406$ & $\$ 15.403 .395$ & $\$ 4.755 .311$ & $\$ 71.478 .071$ \\
\hline DICIEMBRE & $\$ 27.246 .398$ & $\$ 25.274 .374$ & $\$ 15.756 .778$ & $\$ 4.878 .790$ & $\$ 73.156 .340$ \\
\hline
\end{tabular}

Fuente: Elaboración propia con base a datos de valor de fondo de la Superintendencia Financiera

\section{PORTAFOLIO CONSERVADOR}

Anexo 8. Valor fondo conservador año 2016

\begin{tabular}{|c|r|r|r|r|r|r|}
\hline FONDO CONSERVADOR & \multicolumn{1}{|l|}{ PORVENIR } & PROTECCION & COLFONDOS & OLD MUTUAL & \multicolumn{1}{l|}{ TOTAL } \\
\hline ENERO & $\$ 4.623 .229$ & $\$ 3.199 .478$ & $\$ 1.713 .297$ & $\$$ & 663.880 & $\$ 10.199 .884$ \\
\hline FEBRERO & $\$ 4.772 .374$ & $\$ 3.283 .781$ & $\$ 1.753 .458$ & $\$$ & 664.898 & $\$ 10.474 .511$ \\
\hline MARZO & $\$ 4.866 .141$ & $\$ 3.401 .592$ & $\$ 1.825 .163$ & $\$$ & 684.390 & $\$ 10.777 .287$ \\
\hline ABRIL & $\$ 5.096 .711$ & $\$ 3.493 .962$ & $\$ 1.867 .920$ & $\$$ & 695.008 & $\$ 11.153 .601$ \\
\hline MAYO & $\$ 5.291 .926$ & $\$ 3.597 .865$ & $\$ 1.923 .736$ & $\$$ & $\$ 06.720$ & $\$ 11.520 .247$ \\
\hline JUNIO & $\$ 5.377 .798$ & $\$ 3.668 .310$ & $\$ 1.961 .436$ & $\$ 721.415$ & $\$ 11.728 .959$ \\
\hline JULIO & $\$ 5.583 .247$ & $\$ 3.790 .609$ & $\$ 2.033 .752$ & $\$$ & 748.827 & $\$ 12.156 .435$ \\
\hline AGOSTO & $\$ 5.720 .654$ & $\$ 3.865 .629$ & $\$ 2.095 .597$ & $\$$ & 768.937 & $\$ 12.450 .817$ \\
\hline SEPTIEMBRE & $\$ 5.856 .868$ & $\$ 3.970 .719$ & $\$ 2.154 .403$ & $\$ 778.646$ & $\$ 12.760 .635$ \\
\hline OCTUBRE & $\$ 6.036 .757$ & $\$ 4.105 .021$ & $\$ 2.218 .810$ & $\$ 803.354$ & $\$ 13.163 .942$ \\
\hline NOVIEMBRE & $\$ 6.127 .130$ & $\$ 4.188 .206$ & $\$ 2.242 .720$ & $\$ 819.144$ & $\$ 13.377 .201$ \\
\hline DICIEMBRE & $\$ 6.261 .030$ & $\$ 4.307 .559$ & $\$ 2.293 .449$ & $\$ 844.032$ & $\$ 13.706 .070$ \\
\hline
\end{tabular}

Fuente: Elaboración propia con base a datos de valor de fondo de la Superintendencia Financiera 
Anexo 9. Valor fondo conservador año 2015

\begin{tabular}{|c|c|c|c|c|c|c|}
\hline FONDO CONSERVADOR & PORVENIR & PROTECCION & COLFONDOS & OLD MUTUAL & & TOTAL \\
\hline ENERO & $\$ 4.623 .229$ & $\$ 3.199 .478$ & $\$ \quad 1.713 .297$ & $\$ \quad 663.880$ & $\$$ & 10.199 .884 \\
\hline FEBRERO & $\$ 4.772 .374$ & $\$ 3.283 .781$ & $\$ 1.753 .458$ & $\$ \quad 664.898$ & $\$$ & 10.474 .511 \\
\hline MARZO & $\$ 4.866 .141$ & $\$ 3.401 .592$ & $\$ 1.825 .163$ & $\$ \quad 684.390$ & $\$$ & 10.777 .287 \\
\hline ABRIL & $\$ 5.096 .711$ & $\$ 3.493 .962$ & $\$ 1.867 .920$ & $\$ \quad 695.008$ & $\$$ & 11.153 .601 \\
\hline MAYO & $\$ 5.291 .926$ & $\$ 3.597 .865$ & $\$ 1.923 .736$ & $\$ 706.720$ & $\$$ & 11.520 .247 \\
\hline JUNIO & $\$ \quad 5.377 .798$ & $\$ 3.668 .310$ & $\$ 1.961 .436$ & $\$ 721.415$ & $\$$ & 11.728 .959 \\
\hline JULIO & $\$ 5.583 .247$ & $\$ 3.790 .609$ & $\$ 2.033 .752$ & $\$ 748.827$ & $\$$ & 12.156 .435 \\
\hline AGOSTO & $\$ \quad 5.720 .654$ & $\$ 3.865 .629$ & $\$ \quad 2.095 .597$ & $\$ 768.937$ & $\$$ & 12.450 .817 \\
\hline SEPTIEMBRE & $\$ 5.856 .868$ & $\$ 3.970 .719$ & $\$ 2.154 .403$ & $\$ 778.646$ & $\$$ & 12.760 .635 \\
\hline OCTUBRE & $\$ \quad 6.036 .757$ & $\$ 4.105 .021$ & $\$ 2.218 .810$ & $\$ 803.354$ & $\$$ & 13.163 .942 \\
\hline NOVIEMBRE & $\$ 6.127 .130$ & $\$ 4.188 .206$ & $\$ 2.242 .720$ & $\$ \quad 819.144$ & $\$$ & 13.377 .201 \\
\hline DICIEMBRE & $\$ 6.261 .030$ & $\$ 4.307 .559$ & $\$ 2.293 .449$ & $\$ \quad 844.032$ & $\$$ & 13.706 .070 \\
\hline
\end{tabular}

Fuente: Elaboración propia con base a datos de valor de fondo de la Superintendencia Financiera

Anexo 10. Valor fondo conservador año 2014

\begin{tabular}{|c|r|r|r|r|r|r|r|}
\hline FONDO CONSERVADOR & \multicolumn{1}{l|}{ PORVENIR } & \multicolumn{1}{l|}{ PROTECCION } & \multicolumn{1}{l|}{ COLFONDOS } & \multicolumn{1}{l}{ OLD MUTUAL } & \multicolumn{2}{l|}{ TOTAL } \\
\hline ENERO & $\$ 4.211 .392$ & $\$ 2.925 .692$ & $\$ 1.502 .930$ & $\$$ & 546.063 & $\$$ & 9.186 .078 \\
\hline FEBRERO & $\$ 4.256 .345$ & $\$ 2.948 .225$ & $\$ 1.519 .731$ & $\$$ & 556.278 & $\$$ & 9.280 .578 \\
\hline MARZO & $\$ 4.390 .328$ & $\$ 3.028 .520$ & $\$ 1.558 .297$ & $\$$ & 578.295 & $\$$ & 9.555 .440 \\
\hline ABRIL & $\$ 4.412 .051$ & $\$ 3.048 .686$ & $\$ 1.570 .734$ & $\$$ & 593.692 & $\$$ & 9.625 .163 \\
\hline MAYO & $\$ 4.428 .805$ & $\$ 3.070 .116$ & $\$ 1.586 .896$ & $\$$ & 608.239 & $\$$ & 9.694 .056 \\
\hline JUNIO & $\$ 4.452 .049$ & $\$ 3.065 .654$ & $\$ 1.586 .499$ & $\$$ & 611.332 & $\$$ & 9.715 .535 \\
\hline JULIO & $\$ 4.456 .308$ & $\$ 3.067 .560$ & $\$ 1.589 .287$ & $\$$ & 607.267 & $\$$ & 9.720 .422 \\
\hline AGOSTO & $\$ 4.527 .143$ & $\$ 3.112 .922$ & $\$ 1.613 .827$ & $\$$ & 621.359 & $\$$ & 9.875 .252 \\
\hline SEPTIEMBRE & $\$ 4.517 .851$ & $\$ 3.074 .181$ & $\$ 1.625 .784$ & $\$$ & 617.561 & $\$$ & 9.835 .377 \\
\hline OCTUBRE & $\$ 4.531 .872$ & $\$ 3.129 .564$ & $\$ 1.636 .351$ & $\$$ & 628.673 & $\$$ & 9.926 .460 \\
\hline NOVIEMBRE & $\$ 4.567 .709$ & $\$ 3.182 .546$ & $\$ 1.648 .275$ & $\$$ & 646.510 & $\$$ & 10.045 .040 \\
\hline DICIEMBRE & $\$ 4.595 .206$ & $\$ 3.192 .570$ & $\$ 1.661 .920$ & $\$$ & $\$ 651.566$ & $\$ 10.101 .263$ \\
\hline
\end{tabular}

Fuente: Elaboración propia con base a datos de valor de fondo de la Superintendencia Financiera 
Anexo 11. Valor fondo conservador año 2013

\begin{tabular}{|c|l|l|l|l|l|l|l|}
\hline FONDO CONSERVADOR & PORVENIR & PROTECCION & COLFONDOS & SKANDIA & \multicolumn{2}{|l|}{ TOTAL } \\
\hline ENERO & $\$ 2.154 .667$ & $\$ 2.444 .521$ & $\$ 1.275 .016$ & $\$$ & 446.979 & $\$$ & 6.321 .183 \\
\hline FEBRERO & $\$ 2.235 .479$ & $\$ 2.495 .344$ & $\$ 1.321 .356$ & $\$$ & 457.975 & $\$$ & 6.510 .155 \\
\hline MARZO & $\$ 2.292 .817$ & $\$ 2.546 .046$ & $\$ 1.342 .908$ & $\$$ & 466.545 & $\$$ & 6.648 .316 \\
\hline ABRIL & $\$ 2.346 .422$ & $\$ 2.611 .255$ & $\$ 1.360 .432$ & $\$$ & 473.310 & $\$$ & 6.791 .419 \\
\hline MAYO & $\$ 2.345 .571$ & $\$ 2.611 .059$ & $\$ 1.375 .276$ & $\$$ & 467.390 & $\$$ & 6.799 .295 \\
\hline JUNIO & $\$ 2.339 .779$ & $\$ 2.574 .615$ & $\$ 1.336 .101$ & $\$$ & 458.138 & $\$$ & 6.708 .633 \\
\hline JULIO & $\$ 2.386 .913$ & $\$ 2.616 .688$ & $\$ 1.372 .968$ & $\$$ & 472.633 & $\$$ & 6.849 .201 \\
\hline AGOSTO & $\$ 2.426 .957$ & $\$ 2.668 .787$ & $\$ 1.393 .018$ & $\$$ & 484.811 & $\$$ & 6.973 .572 \\
\hline SEPTIEMBRE & $\$ 2.512 .680$ & $\$ 2.774 .447$ & $\$ 1.428 .648$ & $\$$ & 501.294 & $\$$ & 7.217 .069 \\
\hline OCTUBRE & $\$ 2.622 .471$ & $\$ 2.857 .598$ & $\$ 1.481 .042$ & $\$$ & 520.393 & $\$$ & 7.481 .504 \\
\hline NOVIEMBRE & $\$ 2.645 .469$ & $\$ 2.890 .214$ & $\$ 1.488 .713$ & $\$$ & 529.300 & $\$$ & 7.553 .696 \\
\hline DICIEMBRE & $\$ 2.715 .338$ & $\$ 2.963 .782$ & $\$ 1.521 .259$ & $\$$ & 543.558 & $\$$ & 7.743 .937 \\
\hline
\end{tabular}

Fuente: Elaboración propia con base a datos de valor de fondo de la Superintendencia Financiera

Anexo 12. Valor fondo conservador año 2012

\begin{tabular}{|c|ll|ll|ll|ll|c|}
\hline FONDO CONSERVADOR & PORVENIR & \multicolumn{2}{l|}{ PROTECCION } & \multicolumn{2}{l|}{ COLFONDOS } & \multicolumn{2}{l|}{ SKANDIA } & \multicolumn{1}{l|}{ TOTAL } \\
\hline MARZO & $\$ 1.116 .833$ & $\$$ & 768.535 & $\$$ & 734.499 & $\$$ & 225.410 & $\$ 2.845 .277$ \\
\hline ABRIL & $\$ 1.101 .199$ & $\$$ & 795.255 & $\$$ & 756.149 & $\$$ & 228.951 & $\$ 2.881 .554$ \\
\hline MAYO & $\$ 1.159 .819$ & $\$$ & 826.852 & $\$$ & 770.055 & $\$$ & 238.285 & $\$ 2.995 .011$ \\
\hline JUNIO & $\$ 1.187 .911$ & $\$$ & 841.179 & $\$$ & 792.105 & $\$$ & 244.417 & $\$ 3.065 .612$ \\
\hline JULIO & $\$ 1.215 .311$ & $\$$ & 874.760 & $\$$ & 800.263 & $\$$ & 251.982 & $\$ 3.142 .316$ \\
\hline AGOSTO & $\$ 1.260 .696$ & $\$$ & 894.905 & $\$$ & 818.586 & $\$$ & 257.671 & $\$ 3.231 .858$ \\
\hline SEPTIEMBRE & $\$ 1.284 .927$ & $\$$ & 906.307 & $\$$ & 818.769 & $\$$ & 261.031 & $\$ 3.271 .034$ \\
\hline OCTUBRE & $\$ 1.337 .899$ & $\$$ & 939.332 & $\$$ & 862.337 & $\$$ & 271.387 & $\$ 3.410 .954$ \\
\hline NOVIEMBRE & $\$ 1.351 .747$ & $\$$ & 957.729 & $\$$ & 867.275 & $\$$ & 277.735 & $\$ 3.454 .486$ \\
\hline DICIEMBRE & $\$ 1.398 .060$ & $\$$ & 982.640 & $\$$ & 891.406 & $\$$ & 286.727 & $\$ 3.558 .834$ \\
\hline
\end{tabular}

Fuente: Elaboración propia con base a datos de valor de fondo de la Superintendencia Financiera 
Anexo 13. Valor fondo conservador año 2011

\begin{tabular}{|c|l|l|l|l|r|}
\hline FONDO CONSERVADOR & PORVENIR & PROTECCION & HORIZONTE & SKANDIA & \multicolumn{1}{l|}{ TOTAL } \\
\hline ENERO & $\$ 21.456 .541$ & $\$ 20.330 .049$ & $\$ 12.947 .498$ & $\$ 3.857 .835$ & $\$ 58.591 .923$ \\
\hline FEBRERO & $\$ 21.712 .538$ & $\$ 20.578 .711$ & $\$ 13.089 .139$ & $\$ 3.904 .408$ & $\$ 59.284 .795$ \\
\hline MARZO & $\$ 22.466 .723$ & $\$ 21.165 .368$ & $\$ 13.433 .663$ & $\$ 4.028 .278$ & $\$ 61.094 .033$ \\
\hline ABRIL & $\$ 23.016 .643$ & $\$ 21.643 .694$ & $\$ 13.739 .722$ & $\$ 4.149 .885$ & $\$ 62.549 .943$ \\
\hline MAYO & $\$ 23.103 .236$ & $\$ 21.610 .879$ & $\$ 13.770 .091$ & $\$ 4.136 .314$ & $\$ 62.620 .520$ \\
\hline JUNIO & $\$ 23.364 .678$ & $\$ 21.975 .407$ & $\$ 13.968 .022$ & $\$ 4.229 .668$ & $\$ 63.537 .775$ \\
\hline JULIO & $\$ 24.617 .532$ & $\$ 23.103 .382$ & $\$ 14.661 .931$ & $\$ 4.430 .079$ & $\$ 66.812 .924$ \\
\hline AGOSTO & $\$ 25.406 .079$ & $\$ 23.815 .728$ & $\$ 15.104 .597$ & $\$ 4.583 .637$ & $\$ 68.910 .041$ \\
\hline SEPTIEMBRE & $\$ 26.249 .773$ & $\$ 24.557 .123$ & $\$ 15.372 .449$ & $\$ 4.688 .725$ & $\$ 70.868 .071$ \\
\hline OCTUBRE & $\$ 27.232 .382$ & $\$ 25.463 .563$ & $\$ 15.920 .504$ & $\$ 4.900 .343$ & $\$ 73.516 .792$ \\
\hline NOVIEMBRE & $\$ 26.569 .958$ & $\$ 24.749 .406$ & $\$ 15.403 .395$ & $\$ 4.755 .311$ & $\$ 71.478 .071$ \\
\hline DICIEMBRE & $\$ 27.246 .398$ & $\$ 25.274 .374$ & $\$ 15.756 .778$ & $\$ 4.878 .790$ & $\$ 73.156 .340$ \\
\hline
\end{tabular}

Fuente: Elaboración propia con base a datos de valor de fondo de la Superintendencia Financiera

Anexo 14. Valor fondo conservador año 2010

\begin{tabular}{|c|l|l|l|l|l|}
\hline FONDO CONSERVADOR & PORVENIR & PROTECCION & HORIZONTE & SKANDIA & TOTAL \\
\hline ENERO & $\$ 21.456 .541$ & $\$ 20.330 .049$ & $\$ 12.947 .498$ & $\$ 3.857 .835$ & $\$ 58.591 .923$ \\
\hline FEBRERO & $\$ 21.712 .538$ & $\$ 20.578 .711$ & $\$ 13.089 .139$ & $\$ 3.904 .408$ & $\$ 59.284 .795$ \\
\hline MARZO & $\$ 22.466 .723$ & $\$ 21.165 .368$ & $\$ 13.433 .663$ & $\$ 4.028 .278$ & $\$ 61.094 .033$ \\
\hline ABRIL & $\$ 23.016 .643$ & $\$ 21.643 .694$ & $\$ 13.739 .722$ & $\$ 4.149 .885$ & $\$ 62.549 .943$ \\
\hline MAYO & $\$ 23.103 .236$ & $\$ 21.610 .879$ & $\$ 13.770 .091$ & $\$ 4.136 .314$ & $\$ 62.620 .520$ \\
\hline JUNIO & $\$ 23.364 .678$ & $\$ 21.975 .407$ & $\$ 13.968 .022$ & $\$ 4.229 .668$ & $\$ 63.537 .775$ \\
\hline JULIO & $\$ 24.617 .532$ & $\$ 23.103 .382$ & $\$ 14.661 .931$ & $\$ 4.430 .079$ & $\$ 66.812 .924$ \\
\hline AGOSTO & $\$ 25.406 .079$ & $\$ 23.815 .728$ & $\$ 15.104 .597$ & $\$ 4.583 .637$ & $\$ 68.910 .041$ \\
\hline SEPTIEMBRE & $\$ 26.249 .773$ & $\$ 24.557 .123$ & $\$ 15.372 .449$ & $\$ 4.688 .725$ & $\$ 70.868 .071$ \\
\hline OCTUBRE & $\$ 27.232 .382$ & $\$ 25.463 .563$ & $\$ 15.920 .504$ & $\$ 4.900 .343$ & $\$ 73.516 .792$ \\
\hline NOVIEMBRE & $\$ 26.569 .958$ & $\$ 24.749 .406$ & $\$ 15.403 .395$ & $\$ 4.755 .311$ & $\$ 71.478 .071$ \\
\hline DICIEMBRE & $\$ 27.246 .398$ & $\$ 25.274 .374$ & $\$ 15.756 .778$ & $\$ 4.878 .790$ & $\$ 73.156 .340$ \\
\hline
\end{tabular}

Fuente: Elaboración propia con base a datos de valor de fondo de la Superintendencia Financiera 


\section{PORTAFOLIO AGRESIVO}

Anexo 15. Valor fondo agresivo año 2016

\begin{tabular}{|c|r|r|r|r|r|c|}
\hline FONDO DE MAYOR RIESGO & & & & & & \\
& PORVENIR & PROTECCION & COLFONDOS & OLD MUTUAL & TOTAL \\
\hline ENERO & $\$ 212.244$ & $\$ 1.211 .854$ & $\$$ & 66.012 & $\$ 273.539$ & $\$ 1.763 .649$ \\
\hline FEBRERO & $\$ 211.697$ & $\$ 1.209 .651$ & $\$$ & 65.448 & $\$ 277.337$ & $\$ 1.764 .133$ \\
\hline MARZO & $\$ 221.618$ & $\$ 1.254 .229$ & $\$$ & 69.402 & $\$ 293.814$ & $\$ 1.839 .064$ \\
\hline ABRIL & $\$ 222.563$ & $\$ 1.264 .619$ & $\$$ & 71.507 & $\$ 295.094$ & $\$ 1.853 .784$ \\
\hline MAYO & $\$ 228.171$ & $\$ 1.287 .774$ & $\$$ & 72.584 & $\$ 300.576$ & $\$ 1.889 .106$ \\
\hline JUNIO & $\$ 226.171$ & $\$ 1.276 .855$ & $\$$ & 72.858 & $\$ 298.812$ & $\$ 1.874 .696$ \\
\hline JULIO & $\$ 233.395$ & $\$ 1.323 .551$ & $\$$ & 76.785 & $\$ 308.747$ & $\$ 1.942 .478$ \\
\hline AGOSTO & $\$ 239.023$ & $\$ 1.344 .307$ & $\$$ & $\$ 79.319$ & $\$ 316.673$ & $\$ 1.979 .322$ \\
\hline SEPTIEMBRE & $\$ 238.785$ & $\$ 1.347 .701$ & $\$$ & 79.373 & $\$ 319.295$ & $\$ 1.985 .154$ \\
\hline OCTUBRE & $\$ 242.107$ & $\$ 1.363 .665$ & $\$$ & 81.457 & $\$ 326.101$ & $\$ 2.013 .331$ \\
\hline NOVIEMBRE & $\$ 239.080$ & $\$ 1.347 .526$ & $\$$ & 82.249 & $\$ 324.778$ & $\$ 1.993 .633$ \\
\hline DICIEMBRE & $\$ 237.335$ & $\$ 1.378 .338$ & $\$$ & 84.771 & $\$ 334.520$ & $\$ 2.034 .964$ \\
\hline
\end{tabular}

Fuente: Elaboración propia con base a datos de valor de fondo de la Superintendencia Financiera

Anexo 16. Valor fondo agresivo año 2015

\begin{tabular}{|c|c|c|c|c|c|c|}
\hline FONDO DE MAYOR RIESGO & PORVENIR & PROTECCION & COLFONDOS & OLD MUTUAL & \multicolumn{1}{|c|}{ TOTAL } \\
\hline ENERO & $\$ 187.194$ & $\$ 1.097 .591$ & $\$ 49.741$ & $\$ 238.479$ & $\$ 1.573 .005$ \\
\hline FEBRERO & $\$ 195.526$ & $\$ 1.125 .326$ & $\$$ & 52.037 & $\$ 248.254$ & $\$ 1.621 .144$ \\
\hline MARZO & $\$ 196.730$ & $\$ 1.128 .962$ & $\$$ & 52.783 & $\$ 252.303$ & $\$ 1.630 .778$ \\
\hline ABRIL & $\$ 199.046$ & $\$ 1.152 .334$ & $\$$ & 53.937 & $\$ 258.011$ & $\$ 1.663 .328$ \\
\hline MAYO & $\$ 201.324$ & $\$ 1.155 .567$ & $\$$ & 55.625 & $\$ 258.483$ & $\$ 1.670 .999$ \\
\hline JUNIO & $\$ 202.242$ & $\$ 1.160 .637$ & $\$$ & 55.750 & $\$ 258.705$ & $\$ 1.677 .335$ \\
\hline JULIO & $\$ 211.896$ & $\$ 1.213 .326$ & $\$$ & 59.737 & $\$ 272.821$ & $\$ 1.757 .780$ \\
\hline AGOSTO & $\$ 206.390$ & $\$ 1.180 .319$ & $\$$ & 59.517 & $\$ 266.382$ & $\$ 1.712 .609$ \\
\hline SEPTIEMBRE & $\$ 202.638$ & $\$ 1.163 .390$ & $\$$ & 60.425 & $\$ 260.796$ & $\$ 1.687 .249$ \\
\hline OCTUBRE & $\$ 209.575$ & $\$ 1.202 .790$ & $\$$ & 63.444 & $\$ 270.385$ & $\$ 1.746 .194$ \\
\hline NOVIEMBRE & $\$ 212.279$ & $\$ 1.212 .731$ & $\$$ & 64.048 & $\$ 273.570$ & $\$ 1.762 .628$ \\
\hline DICIEMBRE & $\$ 214.806$ & $\$ 1.225 .444$ & $\$$ & 66.313 & $\$ 276.286$ & $\$ 1.782 .849$ \\
\hline
\end{tabular}

Fuente: Elaboración propia con base a datos de valor de fondo de la Superintendencia Financiera 
Anexo 17. Valor fondo agresivo año 2014

\begin{tabular}{|c|c|c|c|c|c|c|c|}
\hline FONDO DE MAYOR RIESGO & & & & & & & \\
& PORVENIR & PROTECCION & COLFONDOS & OLD MUTUAL & \multicolumn{1}{c|}{ TOTAL } \\
\hline ENERO & $\$ 138.956$ & $\$ 910.772$ & $\$$ & 32.395 & $\$ 186.765$ & $\$ 1.268 .888$ \\
\hline FEBRERO & $\$ 144.273$ & $\$$ & 945.538 & $\$$ & 33.706 & $\$ 195.832$ & $\$ 1.319 .349$ \\
\hline MARZO & $\$ 154.741$ & $\$ 992.462$ & $\$$ & 35.155 & $\$ 208.057$ & $\$ 1.390 .416$ \\
\hline ABRIL & $\$ 159.481$ & $\$ 1.007 .844$ & $\$$ & 38.229 & $\$ 211.719$ & $\$ 1.417 .273$ \\
\hline MAYO & $\$ 162.552$ & $\$ 1.015 .993$ & $\$$ & 39.016 & $\$ 214.617$ & $\$ 1.432 .178$ \\
\hline JUNIO & $\$ 166.367$ & $\$ 1.031 .903$ & $\$$ & 39.831 & $\$ 218.808$ & $\$ 1.456 .909$ \\
\hline JULIO & $\$ 170.119$ & $\$ 1.040 .776$ & $\$$ & 40.734 & $\$ 221.315$ & $\$ 1.472 .944$ \\
\hline AGOSTO & $\$ 176.492$ & $\$ 1.078 .962$ & $\$$ & 43.305 & $\$ 229.785$ & $\$ 1.528 .544$ \\
\hline SEPTIEMBRE & $\$ 176.509$ & $\$ 1.056 .850$ & $\$$ & 43.065 & $\$ 227.167$ & $\$ 1.503 .591$ \\
\hline OCTUBRE & $\$ 178.818$ & $\$ 1.070 .551$ & $\$$ & 45.069 & $\$ 233.299$ & $\$ 1.527 .737$ \\
\hline NOVIEMBRE & $\$ 182.373$ & $\$ 1.078 .556$ & $\$$ & 46.589 & $\$ 235.374$ & $\$ 1.542 .892$ \\
\hline DICIEMBRE & $\$ 187.968$ & $\$ 1.098 .283$ & $\$$ & 49.177 & $\$ 237.885$ & $\$ 1.573 .313$ \\
\hline
\end{tabular}

Fuente: Elaboración propia con base a datos de valor de fondo de la Superintendencia Financiera

Anexo 18. Valor fondo agresivo año 2013

\begin{tabular}{|c|c|c|c|c|c|c|c|c|c|}
\hline FONDO DE MAYOR RIESGO & PORVENIR & \multicolumn{2}{|c|}{ PROTECCION } & \multicolumn{2}{|c|}{ COLFONDOS } & \multicolumn{2}{|c|}{ SKANDIA } & \multicolumn{2}{|r|}{ TOTAL } \\
\hline ENERO & $\$ 98.426$ & $\$$ & 877.659 & $\$$ & 24.510 & $\$$ & 168.255 & $\$$ & 1.168 .851 \\
\hline FEBRERO & $\$ 101.418$ & $\$$ & 892.389 & $\$$ & 26.162 & $\$$ & 171.358 & $\$$ & 1.191 .326 \\
\hline MARZO & $\$ 101.776$ & $\$$ & 888.554 & $\$$ & 26.023 & $\$$ & 175.040 & $\$$ & 1.191 .392 \\
\hline ABRIL & $\$ 102.380$ & $\$$ & 887.700 & $\$$ & 26.721 & $\$$ & 174.822 & $\$$ & 1.191 .623 \\
\hline MAYO & $\$ 103.161$ & $\$$ & 884.909 & $\$$ & 26.372 & $\$$ & 174.170 & $\$$ & 1.188 .612 \\
\hline JUNIO & $\$ 100.480$ & $\$$ & 858.690 & $\$$ & 25.502 & $\$$ & 168.126 & $\$$ & 1.152 .798 \\
\hline JULIO & $\$ 103.902$ & $\$$ & 882.132 & $\$$ & 26.601 & $\$$ & 174.736 & $\$$ & 1.187 .372 \\
\hline AGOSTO & \$ 106.974 & $\$$ & 898.117 & $\$$ & 27.664 & $\$$ & 178.078 & $\varphi$ & 1.210 .833 \\
\hline SEPTIEMBRE & $\$ 109.415$ & $\$$ & 925.622 & $\$$ & 29.140 & $\$$ & 185.768 & $\$$ & 1.249 .944 \\
\hline OCTUBRE & $\$ 113.334$ & $\$$ & 945.425 & $\$$ & 29.818 & $\$$ & 190.669 & $\varphi$ & 1.279 .246 \\
\hline NOVIEMBRE & $\$ 112.457$ & $\$$ & 931.459 & $\$$ & 31.106 & $\$$ & 188.252 & $\psi$ & 1.263 .274 \\
\hline DICIEMBRE & $\$ 110.959$ & $\$$ & 935.338 & $\$$ & 31.331 & $\$$ & 194.591 & $\varphi$ & 1.272 .219 \\
\hline
\end{tabular}

Fuente: Elaboración propia con base a datos de valor de fondo de la Superintendencia Financiera 
Anexo 19. Valor fondo agresivo año 2012

\begin{tabular}{|c|c|c|c|c|c|c|c|c|c|c|}
\hline FONDO DE MAYOR RIESGO & \multicolumn{2}{|c|}{ PORVENIR } & \multirow{2}{*}{\multicolumn{2}{|c|}{\begin{tabular}{|l|} 
PROTECCION \\
$\$ 591.931$ \\
\end{tabular}}} & \multicolumn{2}{|c|}{ COLFONDOS } & \multicolumn{2}{|c|}{ SKANDIA } & \multicolumn{2}{|c|}{ TOTAL } \\
\hline ENERO & $\$$ & 59.487 & & & $\$$ & 13.775 & $\$$ & 118.889 & $\$$ & 784.081 \\
\hline FEBRERO & $\$$ & 64.356 & $\$$ & 625.808 & $\$$ & 15.810 & $\$$ & 126.489 & $\$$ & 832.463 \\
\hline MARZO & $\$$ & 67.908 & $\$$ & 647.853 & $\$$ & 16.755 & $\$$ & 131.660 & $\$$ & 864.176 \\
\hline ABRIL & $\$$ & 72.091 & $\$$ & 677.403 & $\$$ & 17.862 & $\$$ & 137.024 & $\$$ & 904.381 \\
\hline MAYO & $\$$ & 73.457 & $\$$ & 675.487 & $\$$ & 18.044 & $\$$ & 136.141 & $\$$ & 903.128 \\
\hline JUNIO & $\$$ & 74.876 & $\$$ & 683.973 & $\$$ & 18.519 & $\$$ & 138.512 & $\$$ & 915.881 \\
\hline JULIO & $\$$ & 77.401 & $\$$ & 708.005 & $\$$ & 19.579 & $\$$ & 141.705 & $\$$ & 946.691 \\
\hline AGOSTO & $\$$ & 79.048 & $\$$ & 725.807 & $\$$ & 20.015 & $\$$ & 144.685 & $\$$ & 969.555 \\
\hline SEPTIEMBRE & $\$$ & 83.833 & $\$$ & 749.354 & $\$$ & 20.702 & $\$$ & 148.453 & $\$$ & 1.002 .342 \\
\hline OCTUBRE & $\$$ & 89.719 & $\$$ & 785.704 & $\$$ & 21.605 & $\$$ & 156.407 & $\$$ & 1.053 .435 \\
\hline NOVIEMBRE & $\$$ & 91.681 & $\$$ & 794.810 & $\$$ & 22.309 & $\$$ & 157.457 & $\$$ & 1.066 .258 \\
\hline DICIEMBRE & $\$$ & 94.750 & $\$$ & 823.354 & $\$$ & 23.010 & $\$$ & 163.394 & $\$$ & 1.104 .508 \\
\hline
\end{tabular}

Fuente: Elaboración propia con base a datos de valor de fondo de la Superintendencia Financiera

Anexo 20. Valor fondo agresivo año 2011

\begin{tabular}{|c|c|c|c|c|c|c|c|c|}
\hline \multirow{2}{*}{$\begin{array}{c}\text { FONDO DE MAYOR RIESGO } \\
\text { ENERO }\end{array}$} & \multicolumn{2}{|c|}{ PORVENIR } & \multirow{2}{*}{\begin{tabular}{|l|} 
PROTECCION \\
$\$ 591.931$ \\
\end{tabular}} & \multicolumn{2}{|c|}{ COLFONDOS } & \multirow{2}{*}{\begin{tabular}{r|} 
SKANDIA \\
118.889 \\
\end{tabular}} & \multicolumn{2}{|c|}{ TOTAL } \\
\hline & $\$$ & 59.487 & & $\$$ & 13.775 & & $\$$ & 784.081 \\
\hline FEBRERO & $\$$ & 64.356 & $\$ 625.808$ & $\$$ & 15.810 & 126.489 & $\$$ & 832.463 \\
\hline MARZO & $\$$ & 67.908 & $\$ 647.853$ & $\$$ & 16.755 & 131.660 & $\$$ & 864.176 \\
\hline ABRIL & $\$$ & 72.091 & $\$ \quad 677.403$ & $\$$ & 17.862 & 137.024 & $\$$ & 904.381 \\
\hline MAYO & $\$$ & 73.457 & $\$ 675.487$ & $\$$ & 18.044 & 136.141 & $\$$ & 903.128 \\
\hline JUNIO & $\$$ & 74.876 & $\$ 683.973$ & $\$$ & 18.519 & 138.512 & $\$$ & 915.881 \\
\hline JULIO & $\$$ & 77.401 & $\$ 708.005$ & $\$$ & 19.579 & 141.705 & $\$$ & 946.691 \\
\hline AGOSTO & $\$$ & 79.048 & $\$ 725.807$ & $\$$ & 20.015 & 144.685 & $\$$ & 969.555 \\
\hline SEPTIEMBRE & $\$$ & 83.833 & $\$ 749.354$ & $\$$ & 20.702 & 148.453 & $\$$ & 1.002 .342 \\
\hline OCTUBRE & $\$$ & 89.719 & $\$ 785.704$ & $\$$ & 21.605 & 156.407 & $\$$ & 1.053 .435 \\
\hline NOVIEMBRE & $\$$ & 91.681 & $\$ 794.810$ & $\$$ & 22.309 & 157.457 & $\$$ & 1.066 .258 \\
\hline DICIEMBRE & $\$$ & 94.750 & $\$ 823.354$ & $\$$ & 23.010 & 163.394 & $\$$ & 1.104 .508 \\
\hline
\end{tabular}

Fuente: Elaboración propia con base a datos de valor de fondo de la Superintendencia Financiera 
Anexo 21. Valor fondo agresivo año 2010

\begin{tabular}{|c|l|l|l|l|l|}
\hline FONDO CONSERVADOR & PORVENIR & PROTECCION & HORIZONTE & SKANDIA & TOTAL \\
\hline ENERO & $\$ 21.456 .541$ & $\$ 20.330 .049$ & $\$ 12.947 .498$ & $\$ 3.857 .835$ & $\$ 58.591 .923$ \\
\hline FEBRERO & $\$ 21.712 .538$ & $\$ 20.578 .711$ & $\$ 13.089 .139$ & $\$ 3.904 .408$ & $\$ 59.284 .795$ \\
\hline MARZO & $\$ 22.466 .723$ & $\$ 21.165 .368$ & $\$ 13.433 .663$ & $\$ 4.028 .278$ & $\$ 61.094 .033$ \\
\hline ABRIL & $\$ 23.016 .643$ & $\$ 21.643 .694$ & $\$ 13.739 .722$ & $\$ 4.149 .885$ & $\$ 62.549 .943$ \\
\hline MAYO & $\$ 23.103 .236$ & $\$ 21.610 .879$ & $\$ 13.770 .091$ & $\$ 4.136 .314$ & $\$ 62.620 .520$ \\
\hline JUNIO & $\$ 23.364 .678$ & $\$ 21.975 .407$ & $\$ 13.968 .022$ & $\$ 4.229 .668$ & $\$ 63.537 .775$ \\
\hline JULIO & $\$ 24.617 .532$ & $\$ 23.103 .382$ & $\$ 14.661 .931$ & $\$ 4.430 .079$ & $\$ 66.812 .924$ \\
\hline AGOSTO & $\$ 25.406 .079$ & $\$ 23.815 .728$ & $\$ 15.104 .597$ & $\$ 4.583 .637$ & $\$ 68.910 .041$ \\
\hline SEPTIEMBRE & $\$ 26.249 .773$ & $\$ 24.557 .123$ & $\$ 15.372 .449$ & $\$ 4.688 .725$ & $\$ 70.868 .071$ \\
\hline OCTUBRE & $\$ 27.232 .382$ & $\$ 25.463 .563$ & $\$ 15.920 .504$ & $\$ 4.900 .343$ & $\$ 73.516 .792$ \\
\hline NOVIEMBRE & $\$ 26.569 .958$ & $\$ 24.749 .406$ & $\$ 15.403 .395$ & $\$ 4.755 .311$ & $\$ 71.478 .071$ \\
\hline DICIEMBRE & $\$ 27.246 .398$ & $\$ 25.274 .374$ & $\$ 15.756 .778$ & $\$ 4.878 .790$ & $\$ 73.156 .340$ \\
\hline
\end{tabular}

Fuente: Elaboración propia con base a datos de valor de fondo de la Superintendencia Financiera 